\title{
EVALUACIÓN DEL DISEÑO SÍSMICO RESILIENTE CONFORME AL MÉTODO DE LAS FUERZAS DE MARCOS DÚCTILES DE ACERO CON DISIPADORES DE ENERGÍA HISTERÉTICOS
}

\author{
Héctor Hernández Ramírez ${ }^{(1)}$ y Arturo Tena Colunga ${ }^{(2)}$
}

\begin{abstract}
RESUMEN
Se presentan los resultados de análisis dinámicos no lineales realizados a doce modelos de edificios que se diseñaron conforme a una metodología que emplea el método de las fuerzas y principios de diseño por capacidad y de fusible estructural, la cual permite obtener diseños sísmicos resilientes de estructuras con base en marcos contraventeados de acero estructural dúctiles con disipadores de energía histeréticos. Se demuestra que los mecanismos de diseño sísmico resiliente corroborados previamente mediante análisis pushover se cumplen para la enorme mayoría de los modelos ante la acción de un registro de aceleración compatible con el espectro elástico considerado en el diseño de los modelos, y si la excitación dinámica rebasa los parámetros de resistencia o demanda supuestos en el diseño de los modelos, se activa exclusivamente la segunda línea de defensa inelástica planeada para el sistema. Con base en los resultados presentados, se confirma que es muy factible diseñar resilientemente al sistema en estudio, incluyendo a edificios altos y esbeltos. Por lo tanto, se pueden emplear con confianza los parámetros globales de diseño sísmico y balances óptimos de rigideces derivados en estudios previos.
\end{abstract}

Palabras clave: diseño sísmico resiliente; disipadores de energía por histéresis; fusibles estructurales; marcos dúctiles de acero estructural

\section{ASSESSMENT OF A FORCE METHOD FOR THE RESILIENT SEISMIC DESIGN OF SPECIAL MOMENT-RESISTING STEEL FRAMES WITH HYSTERETIC ENERGY DISSIPATION DEVICES}

\begin{abstract}
In this paper, the authors present the results of nonlinear dynamic analyses of twelve building models designed according to a methodology based upon the force method, capacity design principles and the concept of structural fuses to achieve resilient seismic designs for special moment-resisting steel frames with hysteretic energy dissipation devices mounted on chevron steel bracing. It is demonstrated that the resilient design mechanism previously checked with pushover analyses is also attained for most studied models with nonlinear dynamic analyses using an acceleration record which is compatible with the elastic design spectrum. Also, it is corroborated that the planned second line
\end{abstract}

Artículo ganador del Décimo Concurso Nacional de Tesis de Maestría 2017 organizado por la SMIS. Se aceptarán comentarios y/o discusiones hasta cinco meses después de su publicación.

(1) Posgrado en Ingeniería Estructural, Universidad Autónoma Metropolitana Azcapotzalco, Av. San Pablo 180, Col. Reynosa Tamaulipas, 02200 Ciudad de México, e-mail: hhruam@hotmail.com

(2) Departamento de Materiales, Universidad Autónoma Metropolitana Azcapotzalco, Av. San Pablo 180, Col. Reynosa Tamaulipas, 02200 Ciudad de México, e-mail: atc@correo.azc.uam.mx 
of inelastic defense is activated if the seismic action surpasses the considered design spectrum. Based upon the obtained results, it is confirmed that it is possible to perform a resilient seismic design for the studied system under the proposed methodology, even for tall and slender buildings. Therefore, the proposed initial stiffness ratio parameters and the global design parameters previously proposed by the authors to use in a code-oriented force method can be used with confidence for the resilient seismic design of this structural system.

Keywords: resilient seismic design; hysteretic energy dissipation devices; structural fuses; ductile steel moment frames

\section{INTRODUCCIÓN}

El control de la respuesta sísmica en México ha tenido su desarrollo a partir de los daños causados por el sismo del 19 de septiembre de 1985 en la ciudad de México (Del Valle, 1988). En los últimos treinta años ha crecido considerablemente el número de estudios experimentales y analíticos sobre dispositivos disipadores de energía propuestos y ensayados a nivel mundial (Tena-Colunga, 2007).

De hecho, desde hace más de dos décadas existen publicaciones relacionadas con el diseño de estructuras con disipadores de energía histeréticos, ya sea validando métodos de diseño con base en el concepto del amortiguamiento viscoso equivalente adicional (Wu y Hanson 1987, Scholl 1993, Foti et al. 1998, Ramírez et al. 2001, Benedetti et al. 2014) o mediante procedimientos de diseño por desplazamiento (por ejemplo, Ramírez et al. 2001, Chen et al. 2007, Symans et al. 2008).

Sin embargo, sólo existen muy pocas investigaciones disponibles que han sido orientadas para promover diseños conforme a reglamentaciones vigentes, ya sea para propuestas de reparación de estructuras (Tena-Colunga y Pérez-Moreno 1994, Tena-Colunga et al. 1996, Tena-Colunga y Vergara 1997, Tena 1998a, Aguiar et al. 2016a), o definiendo parámetros globales de diseño sísmico (Vargas y Bruneau 2006 y 2009, Tena y Nangullasmú 2013, Tena-Colunga y Nangullasmú-Hernández 2015, Nangullasmú y Tena 2016, Tena et al. 2016, Tena y Hernández 2016, Tena-Colunga y Hernández-Ramírez 2017, Tena y Gama 2017) que permitan diseñar estructuras nuevas con DDE mediante el método de las fuerzas conforme a los lineamientos de los reglamentos de diseño sísmico vigentes (Tena y Nangullasmú 2013, Tena-Colunga y Nangullasmú-Hernández 2015, Nangullasmú y Tena 2016, Aguiar et al. 2016b, Tena et al. 2016, Tena y Hernández 2016, Tena-Colunga y Hernández-Ramírez 2017, Tena y Gama 2017).

En los trabajos previamente citados se ha presentado, de manera sucinta, la metodología general de diseño sísmico propuesta por este equipo de investigación para definir parámetros globales de diseño sísmico para estructuras con base en marcos que dispongan de disipadores de energía histeréticos montados en contravientos tipo chevrón como fusibles estructurales, y que puedan insertarse transparentemente en las futuras versiones de los reglamentos y recomendaciones de diseño sísmico de México. El proceso de diseño sísmico paso a paso se ha ejemplificado también con el diseño de un edificio dúctil de acero estructural de 15 niveles con DDE montados en contraventeo chevrón como fusibles estructurales, y su posterior evaluación detallada mediante análisis estáticos y dinámicos no lineales (Hernández 2015, Tena y Hernández 2017). En el presente trabajo se presenta la validación de la robustez del procedimiento de diseño por capacidad y resiliente propuesto mediante la comparación de la respuesta obtenida con análisis dinámicos no lineales paso a paso con respecto a los análisis estáticos no lineales ante carga monótona creciente (pushover) con los que se definieron el mecanismo de diseño resiliente y los parámetros globales de diseño sísmico que se reportan con mayor detalle en Hernández (2015), Tena y Hernández (2016) y Tena-Colunga y Hernández-Ramírez (2017). 


\section{GENERALIDADES DEL ESTUDIO}

Como se describe con mayor detalle en trabajos previos (Hernández 2015, Tena y Hernández 2016 y 2017, Tena-Colunga y Hernández-Ramírez 2017), se diseñaron y estudiaron 270 marcos dúctiles de acero estructural con contravientos de acero tipo chevrón que sirven de soporte a los disipadores histeréticos (figura 1), con base en las siguientes hipótesis que favorecen un diseño sísmico resiliente:

a) los marcos planos son competentes para resistir las cargas verticales y la proporción que les corresponda de las fuerzas sísmicas de diseño, pero respondiendo en el intervalo de comportamiento elástico,

b) el sistema de contraventeo, que sirve de soporte a los disipadores de energía, se comporta elásticamente $\mathrm{y}$,

c) los disipadores histeréticos son los únicos que idealmente deberán trabajar inelásticamente ante la acción de un sismo intenso.

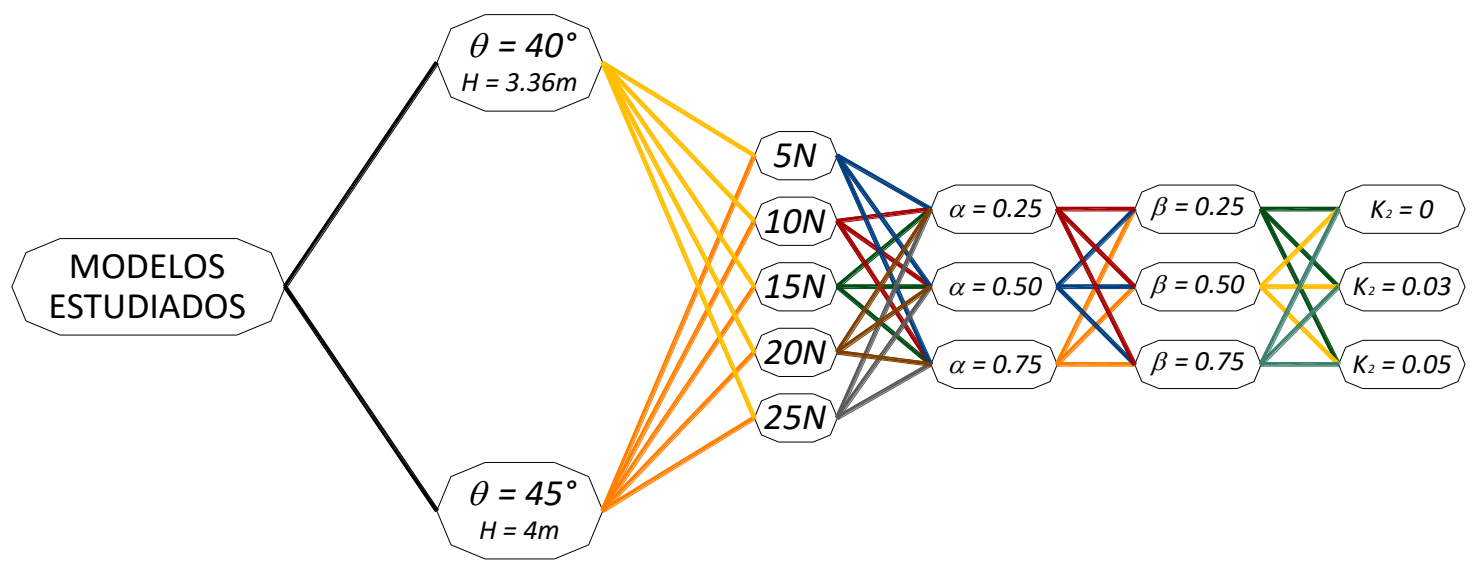

Figura 1. Diagrama de árbol esquemático de los modelos estudiados por Hernández (2015)

Se consideraron marcos de acero que forman parte de edificio de oficinas, localizado en la Ciudad de México, cuyos detalles se describen en trabajos previos (Hernández 2015, Tena y Hernández 2016, TenaColunga y Hernández-Ramírez 2017). Se consideraron cinco alturas diferentes en los edificios, que van de cinco a 25 niveles (figura 1), con incrementos intermedios de cinco niveles (figuras 1 y 2). Para el análisis de los modelos se definen dos ángulos de inclinación en los contravientos, $\theta=40^{\circ}$ y $45^{\circ}$, los cuales tienen altura de entrepiso de $3.36 \mathrm{~m}$ y $4 \mathrm{~m}$ respectivamente, como se ilustra en las elevaciones de la figura 3.

Se propuso que los cambios en las secciones de los elementos de los marcos no coincidieran con los del sistema de contraviento-disipadores intentando, de esta manera práctica, no favorecer la formación de pisos débiles, debido a los contrastes de rigideces y resistencias, como se ilustra esquemáticamente en la figura 2. 


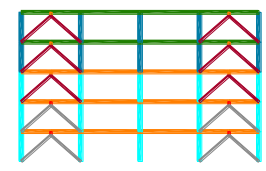

5 niveles

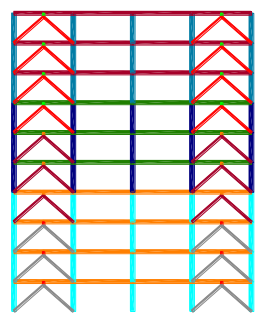

10 niveles

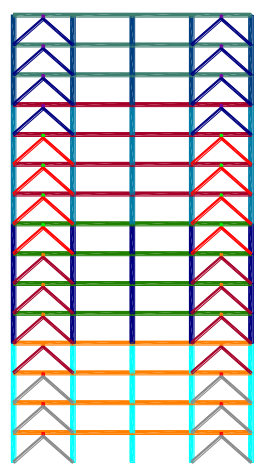

15 niveles

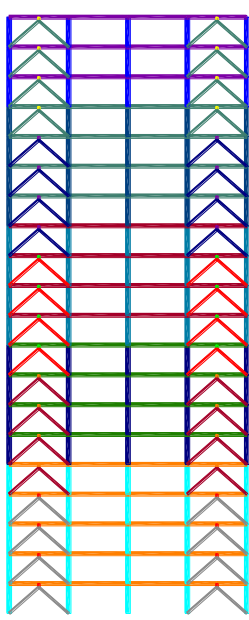

20 niveles

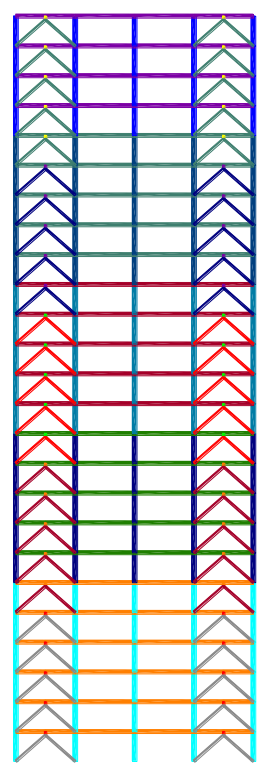

25 niveles

Figura 2. Representación de los cambios de sección para los marcos de acero estructural estudiados. Los colores ilustran esquemáticamente los cambios de sección, pero no tienen relación entre un modelo y otro (es decir, no indican que se trate de la misma sección transversal)
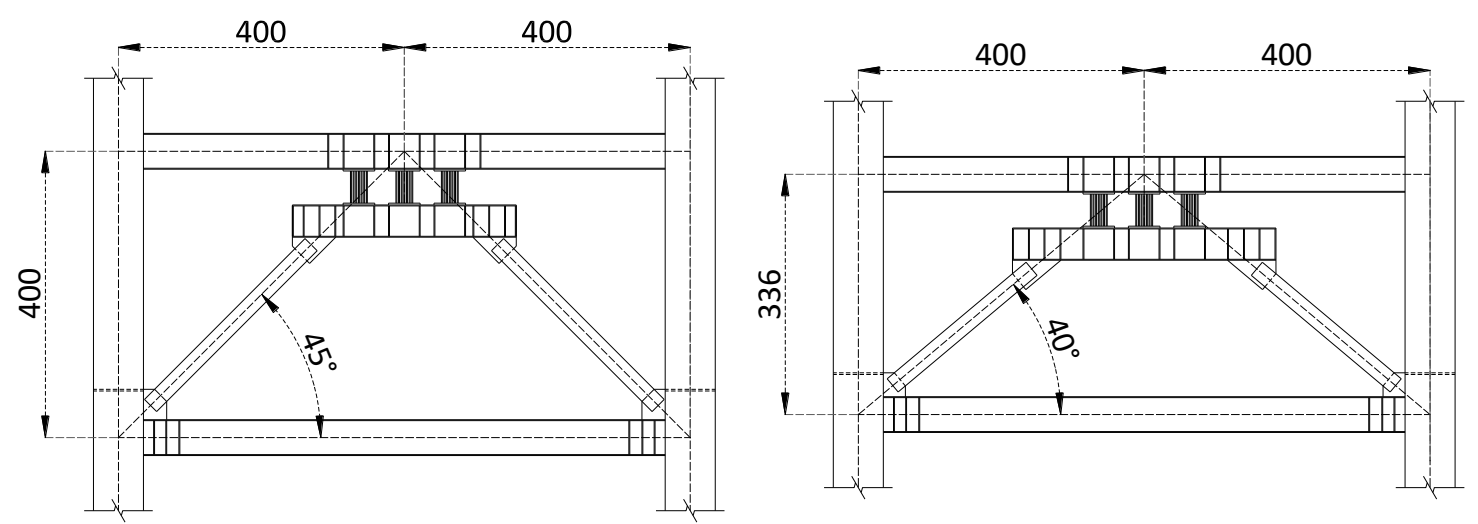

Figura 3. Configuración de crujías contraventeadas (dimensiones en centímetros)

\section{Parámetros estructurales}

Como se describe con mayor detalle en trabajos previos (Hernández 2015, Tena y Hernández 2016, Tena-Colunga y Hernández-Ramírez 2017), se estudiaron parámetros estructurales con la finalidad de definir valores que permitan, en la medida de lo posible y práctico, un diseño sísmico resiliente, donde los marcos de acero estructural permanezcan esencialmente elásticos o con una inelasticidad muy reducida y sean los disipadores de energía quienes concentren la deformación inelástica, dado que éstos pueden reemplazarse de una manera más rápida y limpia, de existir, por supuesto, el presupuesto suficiente para ello.

Las variables estudiadas fueron (figura 1): 
a) La proporción de la rigidez lateral que aportan los marcos $\left(K_{\text {marco }}\right)$ con respecto a la rigidez lateral total del sistema marco-contraviento disipador $\left(K_{\text {total }}\right)$ :

$$
\alpha=\frac{K_{\text {marco }}}{K_{\text {total }}}
$$

b) La proporción de la rigidez lateral elástica del disipador de energía $\left(K_{D D E}\right)$ con respecto a la rigidez lateral de los contravientos de soporte $\left(K_{\text {diag }}\right)$ :

$$
\beta=\frac{K_{D D E}}{K_{\text {diag }}}
$$

c) La variación en la pendiente posterior a la fluencia que desarrollan los disipadores de energía histeréticos, normalizada con respecto a la pendiente elástica inicial, identificada por la variable $K_{2}$ (figura 4).

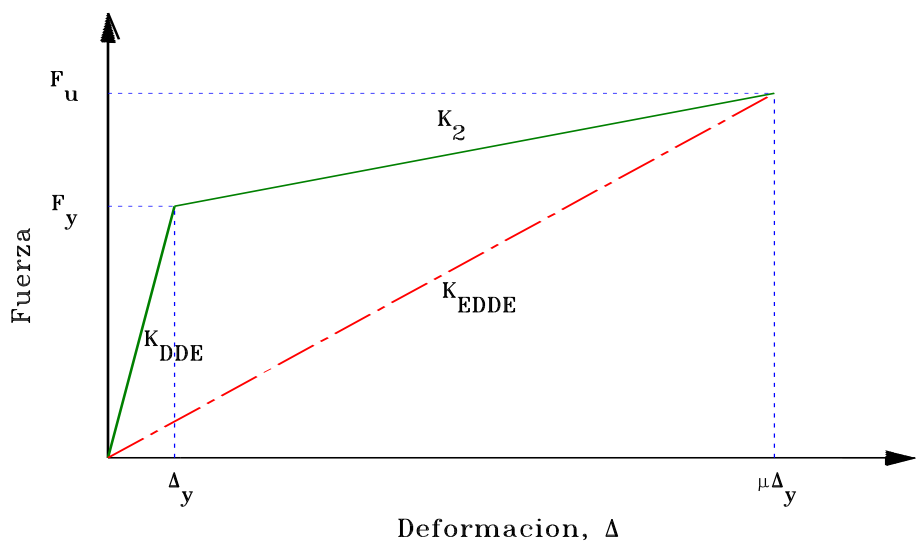

Figura 4. Curva típica fuerza-deformación de un disipador histerético con comportamiento bilineal

\section{DEFINICIÓN DE MECANISMOS SÍSMICOS ÚLTIMOS RESILIENTES}

Los 270 modelos en estudio se diseñaron mediante un procedimiento basado en las rigideces elásticas iniciales de los marcos con disipadores que se presenta con mayor detalle en Hernández (2015) y Tena y Hernández $(2016,2017)$. Para tener una referencia de comparación definida, se consideró para todos los modelos un cortante de diseño sísmico efectivo del $10 \%$ del peso total de la estructura $\left(V / W_{t}=0.10\right)$, que corresponde al cortante basal efectivo de diseño de una estructura dúctil ( $Q=4$ y $R=2)$ de la zona del lago más demandada de la Ciudad de México según lo establecido en las NTCS-04 (2004). Asimismo, la ductilidad local objetivo de los disipadores histeréticos se supuso $\mu_{d}=10$.

El procedimiento de diseño propuesto involucra un proceso iterativo, además de incluir conceptos del diseño por capacidad, donde se realiza el diseño secuencialmente del elemento más débil (donde se disipará la energía) al más fuerte (el que deberá permanecer elástico). Se pretende, por lo tanto, promover una filosofía de diseño sísmico resiliente donde los disipadores de energía sean los fusibles estructurales ante cargas laterales y, por ello, sean los únicos elementos que deberían ser reemplazados después de un sismo intenso. 


\section{Definición de un mecanismo resiliente}

El criterio empleado para definir el mecanismo último aceptable es que éste fuera resiliente, en contraste con el criterio del mecanismo de prevención de colapso fomentado por muchos reglamentos de diseño sismorresistente del mundo, que básicamente promueven como aceptable que una estructura quede muy dañada y prácticamente inservible después del sismo de diseño, o ésta no se pueda utilizar por meses o años mientras se define y se implementa una estrategia efectiva de reestructuración para prolongar su vida útil. Por ello, el mecanismo último aceptable se definió vigilando que, al alcanzar la ductilidad objetivo de los disipadores de energía $\left(\mu_{d}\right)$, los demás elementos estructurales permanecieran esencialmente elásticos, sobre todo los contravientos de soporte y las columnas, aceptando cuando más la fluencia incipiente de las vigas como una segunda fuente adecuada de inelasticidad que pudiera hacer frente a acciones extremas que superen las consideradas en su diseño.

\section{Escala de colores para identificar demandas inelásticas}

Para comprobar las premisas generales de diseño resiliente expuestas anteriormente, se requirió monitorear la potencial respuesta inelástica de todos los elementos estructurales, no únicamente la de los disipadores de energía. Por ello, además de definir las curvas bilineales de los disipadores, se modelaron también la capacidad de rotación plástica teórica de las vigas y de las columnas y el potencial pandeo de los contravientos. Para los elementos de acero, sus diagramas de interacción y momento-curvatura plásticos se calcularon a partir de la teoría clásica de plasticidad para perfiles y secciones cajón de acero, como se detalla en Hernández (2015) para el caso particular de la sección cajón.

Como en el estudio paramétrico se diseñaron y analizaron 270 distintos modelos (figura 1), para poder analizar y discrimar qué combinaciones de parámetros globales de diseño cumplían con el objetivo de obtener el mecanismo resiliente anteriormente descrito, se definió una escala de colores cálidos para identificar de manera sencilla y esquemática el nivel de demanda inelástica de los distintos elementos estructurales. La escala de colores cálidos para los disipadores de energía se fijó en función de las demandas de ductilidad que desarrollaron los modelos, y se identifican en la figura 5a. Por congruencia, también se definió una escala para los contravientos (figura 5b), con la esperanza de no ser requerida, como de hecho sucedió en los 270 casos en estudio. Para las vigas de sección I de acero estructural, la curva se comporta simétrica tanto para la flexión positiva como negativa (figura $5 \mathrm{c}, P / P_{y}=0$ ). Para las columnas de sección cajón, se considera el efecto de la fuerza axial sobre la resistencia nominal a flexión de las columnas, esto es, que para relaciones de $P / P_{y}>0$ el momento plástico disminuye (figura $5 \mathrm{c}$ ).

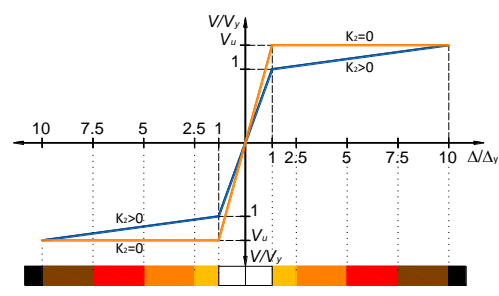

a) Disipadores de energía

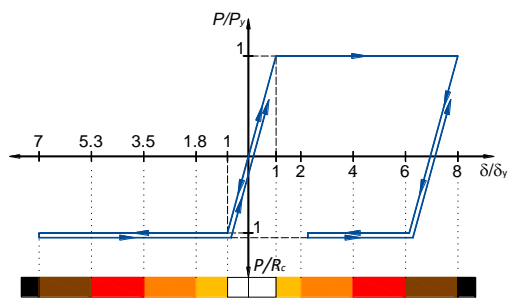

b) Contravientos

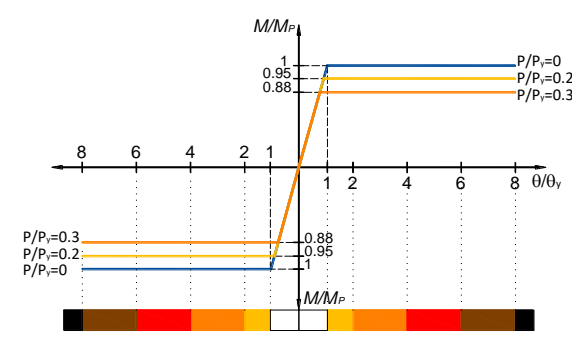

c) Vigas y Columnas

Figura 5. Escala de colores cálidos para identificar demandas inelásticas

Los disipadores con comportamiento elastoplástico perfecto $\left(K_{2}=0\right)$ o con pendientes posteriores a la fluencia efectivas $\left(K_{2}>0\right)$ se diseñaron desde un inicio para proporcionar la misma fuerza última $V_{u}$ a la ductilidad objetivo $\mu_{d}$. En la figura 5 a se aprecia que el cortante de fluencia de los disipadores $\left(V_{y}\right)$ es menor 
para los disipadores con pendientes posteriores a la fluencia $K_{2}>0$ que para comportamiento elastoplástico perfecto $\left(K_{2}=0\right) \mathrm{y}$, por ello, los disipadores donde $K_{2} \neq 0$ comienzan a trabajar antes en el intervalo de comportamiento inelástico que los disipadores elastoplásticos perfectos.

\section{Balances de rigidez}

Con base en el análisis detallado de los mapeos de fluencias inelásticas y demandas de ductilidad de los disipadores, se definieron los balances de los parámetros estructurales de rigidez $\alpha$ y $\beta$ para los modelos estudiados que lideran a un diseño sísmico resiliente conforme al concepto que los disipadores de energía por histéresis trabajan como fusibles estructurales.

En las tablas 1 y 2 se presentan los intervalos de combinaciones de los parámetros $\alpha$ y $\beta$ para los cuales se recomienda el empleo de estructuras con disipadores de energía cuando el ángulo de inclinación de los contravientos con respecto al plano horizontal es $\theta=40^{\circ}$ o $\theta=45^{\circ}$ respectivamente. Para este caso, se decidió utilizar el siguiente código de colores en las tablas para relacionar los parámetros $\alpha, \beta$ y $Q$ con el siguiente comportamiento observado en los mapeos de fluencia de los elementos del marco: a) sin color cuando el marco se comporta elástico o existen menos de cinco extremos de elementos estructurales con fluencia incipiente, b) con amarillo claro cuando existen más de cinco extremos de vigas con fluencia incipiente, pero no más de 15, c) con amarillo cuando existen más de 15 extremos de vigas con fluencia incipiente, pero menos de 30, d) con naranja cuando se presentan más de 30 extremos de vigas con fluencias y, e) con rojo carmín cuando la magnitud de las fluencias en los extremos de las vigas son moderadas o grandes, independientemente del número de éstas. Cabe señalar que el color del parámetro $\alpha$ está relacionado cuando se observan fluencias en las vigas y se indica con la máxima intensidad indicada en $\beta$ para sus combinaciones con $K_{2} / K_{D D E}$, con fines de salvar espacio al momento de preparar y sintetizar esta información. Por ello, si en un grupo de información existen celdas de $\beta$ sombreadas en amarillo y naranja, para ese grupo se identifica en naranja el valor de $\alpha$ para el cual se obtienen esos comportamientos.

De los resultados mostrados en la tabla 1 se puede concluir que, para el cortante basal de diseño considerado $\left(V / W_{t}=0.10\right)$, el diseño de marcos dúctiles de acero con dispositivos disipadores de energía por histéresis montados en contravientos chevrón con ángulos de inclinación $\theta=40^{\circ}$ que funcionen con el concepto del fusible estructural (marco elástico, disipadores inelásticos) es altamente probable para casi todas las alturas (5 a 25 niveles) y combinaciones de parámetros en estudio: $0.25 \leq \alpha \leq 0.75,0.25 \leq \beta \leq 0.75 \mathrm{y}$ $0.0 \leq K_{2} / K_{D D E} \leq 0.05$. Las excepciones donde se presentan algunas fluencias incipientes en vigas (color amarillo) son para las siguientes combinaciones: a) $\alpha=0.75$ y $\beta=0.25$ con $K_{2} / K_{D D E}=0.0$ y $K_{2} / K_{D D E}=0.03$ para los modelos de 15 niveles y, b) $\alpha=0.75, \beta=0.25$ y $K_{2} / K_{D D E}=0.03$ para los modelos de 20 y 25 niveles. Solamente se obtienen fluencias moderadas en vigas (color naranja) cuando $\alpha=0.75, \beta=0.25$ y $K_{2} / K_{E L D}=0.0$ para los modelos de 20 y 25 niveles.

En contraste, se puede concluir a partir del análisis de los resultados mostrados en la tabla 2 que el intervalo de combinaciones de los parámetros $\alpha, \beta$ y $K_{2} / K_{D D E}$ para los cuales se pueden diseñar los marcos dúctiles de acero estructural con disipadores de energía histeréticos montados en contravientos chevrón bajo el concepto del fusible estructural se reduce notablemente cuando el ángulo del contraviento se incrementa $\theta=45^{\circ}$. Únicamente fue posible para todos los modelos de cinco niveles, y también los modelos de 10 niveles, excepto cuando $\alpha=0.75$ y $\beta=0.25$, particularmente para comportamiento elastoplástico perfecto $\left(K_{2} / K_{D D E}=0.0\right)$, donde se obtiene un código naranja. A partir de los modelos de 15 niveles se comienzan a observar un número importante de fluencias en vigas cuando $\alpha=0.75$ y $\beta=0.25$, y crecen para los modelos de 20 niveles, donde se aprecian fluencias importantes en vigas cuando: a) $\alpha=0.75$ y $\beta=0.25 \mathrm{y}$, b) $\alpha=0.75 \mathrm{y}$ $\beta=0.50$. Para los modelos de 25 niveles, la fluencia en vigas es inevitable para todas las combinaciones de $\alpha$ y $\beta$ en estudio, pero tiende a disminuir a medida que tanto $\beta$ como $K_{2} / K_{D D E}$ se incrementan. 
Tabla 1.Intervalo de valores recomendados para los parámetros estructurales cuando $\theta=40^{\circ}$, marcos dúctiles de acero estructural

\begin{tabular}{|c|c|c|c|c|c|c|}
\hline \multirow{2}{*}{ Niveles } & \multirow{2}{*}{\multicolumn{2}{|c|}{$\alpha$}} & \multirow{2}{*}{$K_{2} / K_{D D E}$} & \multicolumn{3}{|c|}{$Q$} \\
\hline & & & & $\beta=0.25$ & $\beta=0.5$ & $\beta=0.75$ \\
\hline \multirow{3}{*}{5} & \multirow{3}{*}{$0.25-$} & \multirow{3}{*}{0.75} & 0 & 5.8 & $4.5-4.3$ & $4.2-3.7$ \\
\hline & & & 0.03 & $5.4-6.4$ & 4.9 & $4.5-4.2$ \\
\hline & & & 0.05 & $5.6-6.4$ & $5.0-5.2$ & $4.7-4.4$ \\
\hline \multirow{3}{*}{10} & \multirow{3}{*}{$0.25-$} & \multirow{3}{*}{0.75} & 0 & $3.9-3.7$ & 3.7 & 3.4 \\
\hline & & & 0.03 & $4.4-4.0$ & $4.1-4.3$ & $3.7-3.9$ \\
\hline & & & 0.05 & $4.6-4.3$ & $4.3-4.6$ & $3.9-4.1$ \\
\hline \multirow{3}{*}{15} & \multirow{3}{*}{$0.25-$} & \multirow{3}{*}{0.75} & 0 & $3.2-3.0$ & $3.1-3.0$ & $2.9-3.1$ \\
\hline & & & 0.03 & $3.6-3.1$ & $3.4-3.5$ & $3.3-3.6$ \\
\hline & & & 0.05 & $3.8-3.4$ & $3.6-3.9$ & $3.5-3.9$ \\
\hline \multirow{3}{*}{20} & \multirow{3}{*}{$0.25-$} & \multirow{3}{*}{0.75} & 0 & $2.9-2.7$ & $2.8-2.6$ & $2.7-2.6$ \\
\hline & & & 0.03 & $3.2-2.8$ & $3.1-2.8$ & $3.0-2.9$ \\
\hline & & & 0.05 & $3.4-2.8$ & $3.3-3.1$ & 3.2 \\
\hline \multirow{3}{*}{25} & \multirow{3}{*}{$0.25-$} & \multirow{3}{*}{0.75} & 0 & $2.8-2.6$ & $2.6-2.5$ & $2.5-2.6$ \\
\hline & & & 0.03 & $2.9-2.8$ & $2.7-2.8$ & $2.7-2.8$ \\
\hline & & & 0.05 & $3.0-2.8$ & $2.9-\quad 2.9$ & 2.9 \\
\hline
\end{tabular}

Tabla 2.Intervalo de valores recomendados para los parámetros estructurales cuando $\theta=45^{\circ}$, marcos dúctiles de acero estructural

\begin{tabular}{|c|c|c|c|c|c|c|}
\hline \multirow{2}{*}{ Niveles } & \multirow{2}{*}{\multicolumn{2}{|c|}{$\alpha$}} & \multirow{2}{*}{$K_{2} / K_{D D E}$} & \multicolumn{3}{|c|}{$Q$} \\
\hline & & & & $\beta=0.25$ & $\beta=0.5$ & $\beta=0.75$ \\
\hline \multirow{3}{*}{5} & \multirow{3}{*}{$0.25-$} & \multirow{3}{*}{0.75} & 0 & $4.7-5.2$ & $4.0-4.1$ & $3.8-3.5$ \\
\hline & & & 0.03 & $5.1-5.6$ & $4.5-4.7$ & $4.2-4.0$ \\
\hline & & & 0.05 & $5.3-5.7$ & $4.7-5.0$ & $4.4-4.2$ \\
\hline \multirow{3}{*}{10} & \multirow{3}{*}{$0.25-$} & \multirow{3}{*}{0.75} & 0 & $3.5-3.5$ & $3.3-3.1$ & $3.2-3.1$ \\
\hline & & & 0.03 & $4.0-3.6$ & $3.7-3.6$ & 3.6 \\
\hline & & & 0.05 & $4.3-3.6$ & $4.0-3.9$ & $3.8-3.9$ \\
\hline \multirow{3}{*}{15} & \multirow{3}{*}{$0.25-$} & \multirow{3}{*}{0.75} & 0 & $2.9-2.9$ & $2.8-2.6$ & $2.7-2.6$ \\
\hline & & & 0.03 & $3.3-3.0$ & $3.1-2.9$ & $2.9-3.1$ \\
\hline & & & 0.05 & $3.5-3.1$ & $3.3-3.0$ & $3.1-3.4$ \\
\hline \multirow{3}{*}{20} & \multirow{3}{*}{$0.25-$} & \multirow{3}{*}{0.75} & 0 & $2.6-2.7$ & $2.5-2.4$ & $2.6-2.3$ \\
\hline & & & 0.03 & $3.0-2.6$ & $2.9-2.5$ & $2.8-2.5$ \\
\hline & & & 0.05 & $3.2-2.7$ & $3.0-2.6$ & $2.9-2.7$ \\
\hline \multirow{3}{*}{25} & \multirow{3}{*}{$0.25-$} & \multirow{3}{*}{0.75} & 0 & $2.9-2.7$ & $2.7-2.5$ & $2.6-2.4$ \\
\hline & & & 0.03 & $3.0-2.7$ & $2.6-2.6$ & $2.5-2.5$ \\
\hline & & & 0.05 & $3.0-2.6$ & $2.6-2.5$ & $2.5-2.7$ \\
\hline
\end{tabular}

Por lo tanto, a partir del análisis de los resultados mostrados en las tablas 1 y 2, se puede concluir que para el cortante basal efectivo de diseño $V / W_{t}=0.10$ considerado, a medida que los modelos van creciendo en número de pisos (se van haciendo más esbeltos), empiezan a aparecer fluencias en vigas de los marcos a medida que: a) la rigidez elástica del disipador se reduce con respecto a la de los contravientos de soporte (el parámetro $\beta$ disminuye), b) la rigidez lateral elástica del marco crece con respecto a la del sistema contraviento-disipador (el parámetro $\alpha$ aumenta) y, c) la pendiente efectiva posterior a la fluencia $\left(K_{2} / K_{D D E}\right)$ se reduce, particularmente para un comportamiento elastoplástico perfecto $\left(K_{2}=0\right)$. De igual manera, la acción inelástica en los elementos del marco (vigas en este caso) se incrementa a medida que el ángulo de inclinación de los contravientos con respecto al plano horizontal $(\theta)$ crece, a pesar de que en este estudio se consideró un incremento de $\theta$ muy pequeño (solo cinco grados). Lo anterior ya se había deducido analíticamente en estudios previos (Tena 2000), al derivar la ecuación no lineal para marcos de una sola crujía que contaban de dispositivos disipadores de energía montados en contravientos chevrón, si se consideraba que el contraviento permanece elástico y el disipador tiene un comportamiento bilineal y puede desarrollar una ductilidad dada.

\section{Parámetros globales de diseño sísmico conforme a los lineamientos de diseño sísmico de México}

La determinación de parámetros globales de diseño sísmico, como el factor de comportamiento sísmico $Q$, el factor de reducción por sobrerresistencia $R$, la distorsión de entrepiso a la fluencia $\left(\Delta_{y}\right)$ y la distorsión última de diseño $\left(\Delta_{u}\right)$ compatible con un diseño sísmico resiliente donde los disipadores de energía trabajen como fusibles estructurales a la máxima ductilidad posible, garantizando que la estructura competente a cargas verticales permanezca esencialmente elástica, se presenta y discute con detalle en Hernández (2015), Tena y Hernández (2016) y Tena-Colunga y Hernández-Ramírez (2017). A continuación, se resumen algunos aspectos relevantes arrojados de ese estudio detallado.

Los valores estimados para la ductilidad global del sistema (factor de comportamiento sísmico $Q$ ) se obtuvieron para todos los modelos y balances de rigideces $\alpha$ y $\beta$ considerados en este estudio, y se reportan 
de manera sintética en las tablas 1 y 2 . De estas tablas se observa que el factor $Q$ se reduce a medida que: a) aumenta el número de pisos, b) $\beta$ aumenta, c) $K_{2} / K_{D D E}$ disminuye y, d) $\alpha$ disminuye. Sin embargo, cabe señalar que el impacto de $\alpha$ parece ser menor que para los otros parámetros en este sistema estructural.

De acuerdo con los reglamentos y manuales de diseño sísmico en México vigentes hasta fines de 2017, el máximo valor permitido para el factor de comportamiento sísmico $Q$ es $Q=4$. Se aprecia en las tablas 1 y 2 que se pueden obtener valores cercanos y mayores para los modelos de cinco y 10 niveles (si $K_{2} \neq 0$ ), pero éstos se reducen para alturas mayores a 15 niveles y para 25 niveles alcanzan un valor cercano a $Q=3.0$, si se mantiene al sistema con el concepto de un diseño resiliente donde los disipadores de energía trabajen como fusibles estructurales. Por supuesto, se pueden obtener valores más grandes si se permite una fluencia severa en las vigas del marco, pero ¿cuál sería el fin de perder las ventajas de un diseño resiliente donde se asegura una respuesta elástica del marco y, por ende, se garantiza la operación del inmueble posterior a la ocurrencia de un sismo intenso, con interrupciones mínimas que pueden ser programadas para reemplazar a los disipadores de energía que así lo requieran?

Los factores de sobrerresistencia obtenidos variaron en los siguientes intervalos: a) $1.8 \leq R \leq 2.7$ cuando $\alpha=0.25$, b) $2.3 \leq R \leq 3.3$ cuando $\alpha=0.50$ y, c) $2.9 \leq R \leq 4.4$ cuando $\alpha=0.75$. El parámetro con mayor influencia en el factor de sobrerresistencia es el balance de rigidez entre el marco y el sistema global, $\alpha$, pues a medida que $\alpha$ se incrementa, el marco toma una mayor proporción de la carga lateral y, dado la secuencia en un diseño por capacidad, las vigas y las columnas son sobrediseñadas con respecto a los dispositivos disipadores de energía. El segundo parámetro con mayor influencia es la pendiente posterior a la fluencia $K_{2}$; de hecho, se obtienen factores de sobrerresistencia mayores a medida que $K_{2}$ disminuye. El impacto del parámetro $\beta$ en la sobrerresistencia es menos clara, generalmente al incrementar el valor de $\beta$ la sobrerresistencia tiende a disminuir o mantenerse con el mismo valor, para la mayoría de los casos. Cuando el valor del ángulo de los contravientos $\theta$ se incrementa, la sobrerresistencia disminuye en general. Se confirma nuevamente que la sobrerresistencia depende tanto del sistema, como de la configuración estructural, algo que debiera ser reconocido, o al menos comentado, en todos los reglamentos de diseño sísmico de México.

Se encontró que las distorsiones de entrepiso a la fluencia $\left(\Delta_{y}\right)$ para este sistema estructural varían entre $0.08 \%$ y $0.43 \%$, y las siguientes tendencias generales de $\Delta_{y}$ con los parámetros en estudio (Hernández 2015, Tena y Hernández 2016): a) a medida que $\alpha$ aumenta, $\Delta_{y}$ aumenta, b) a medida que $\beta$ aumenta, $\Delta_{y}$ disminuye $\mathrm{y}, \mathrm{c}$ ) a medida que el número de pisos aumenta, $\Delta_{y}$ tiende a aumentar. Además, también se observa de los resultados obtenidos que las distorsiones $\Delta_{y}$ para $\theta=45^{\circ}$ fueron mayores que las correspondientes a $\theta=40^{\circ}$ por lo que, al parecer, a medida que $\theta$ aumenta, $\Delta_{y}$ aumenta.

Las distorsiones últimas promedio de entrepiso se obtuvieron calculando el promedio para cada relación de $\alpha$ y $\beta$ respectivamente, y se usaron únicamente los entrepisos donde los disipadores de energía (y eventualmente alguna viga) tenían deformaciones inelásticas, es decir, que los entrepisos que permanecen con comportamiento elástico no se tomaron en cuenta para el cálculo de las distorsiones promedio. En el estudio paramétrico se apreció que, en general, las distorsiones últimas se incrementan con la altura y con el ángulo de inclinación del contraviento, $\theta$ (Hernández 2015, Tena y Hernández 2016). Las distorsiones últimas desarrolladas a la ductilidad objetivo de los disipadores $\mu_{d} \approx 10$ conforme a un diseño resiliente resultaron inferiores al 1.3\%, lo que indica y señala claramente que en un marco dúctil de acero bien diseñado con disipadores de energía montados en contravientos chevrón, no se necesitan desarrollar distorsiones de entrepiso muy altas para disipar una gran cantidad de energía y desarrollar ductilidades globales razonables. Dado que las distorsiones últimas máximas son moderadas, resulta claro que emplear disipadores de energía histeréticos diseñados con conceptos de resilencia y fusible estructural constituyen 
también una opción razonable para minimizar el daño en contenidos sensibles al desplazamiento y a elementos no estructurales que se encuentren debidamente desligados del sistema estructural principal.

\section{EVALUACIÓN DEL MECANISMO RESILIENTE MEDIANTE ANÁLISIS NO LINEALES}

Los resultados del extenso estudio paramétrico descrito, principalmente todos los resultados obtenidos de los análisis estáticos no lineales ante carga monótona-creciente (pushover) se reportan con detalle en Hernández (2015) y en otros trabajos previamente publicados (Tena y Hernández 2016, TenaColunga y Hernández-Ramírez 2017).

\section{Modelos seleccionados}

En este trabajo, con la finalidad de ilustrar que el procedimiento de diseño es adecuado y razonable ante la acción de sismos intensos, incluyendo aquéllos en que las acciones rebasen a las consideradas en los espectros de diseño sísmico elásticos, se comparan los resultados de los análisis estáticos no lineales ante carga monótona creciente ("pushover") y dinámicos paso a paso no lineales de doce de los 270 modelos, que por facilidad de interpretación se identifican en la tabla 3.

Tabla 3. Modelos estudiados para comparar los resultados de análisis estáticos y dinámicos no lineales

\begin{tabular}{ccccccc}
\hline Modelo & Niveles & $\boldsymbol{\theta}$ & $\boldsymbol{\alpha}$ & $\boldsymbol{\beta}$ & $\boldsymbol{k}_{2} / \boldsymbol{k}_{\boldsymbol{D D E}}$ & $\boldsymbol{T}(\boldsymbol{s})$ \\
\hline $\mathrm{m} 5 \alpha 75 \beta 25$ & 5 & $45^{0}$ & 0.75 & 0.25 & 0.05 & 0.762 \\
$\mathrm{~m} 10 \alpha 25 \beta 25$ & 10 & $45^{0}$ & 0.25 & 0.25 & 0.00 & 1.240 \\
$\mathrm{~m} 10 \alpha 75 \beta 25-1$ & 10 & $45^{0}$ & 0.75 & 0.25 & 0.00 & 1.302 \\
$\mathrm{~m} 10 \alpha 75 \beta 25-2$ & 10 & $45^{0}$ & 0.75 & 0.25 & 0.03 & 1.343 \\
$\mathrm{~m} 10 \alpha 75 \beta 25-3$ & 10 & $45^{0}$ & 0.75 & 0.25 & 0.05 & 1.372 \\
$\mathrm{~m} 15 \alpha 75 \beta 25-1$ & 15 & $45^{0}$ & 0.75 & 0.25 & 0.05 & 1.842 \\
$\mathrm{~m} 15 \alpha 75 \beta 25-2$ & 15 & $40^{0}$ & 0.75 & 0.25 & 0.05 & 1.547 \\
$\mathrm{~m} 15 \alpha 50 \beta 50$ & 15 & $40^{0}$ & 0.50 & 0.50 & 0.03 & 1.550 \\
$\mathrm{~m} 20 \alpha 50 \beta 75-1$ & 20 & $45^{0}$ & 0.50 & 0.75 & 0.05 & 2.162 \\
$\mathrm{~m} 20 \alpha 50 \beta 75-2$ & 20 & $40^{0}$ & 0.50 & 0.75 & 0.05 & 1.773 \\
$\mathrm{~m} 25 \alpha 75 \beta 25$ & 25 & $45^{0}$ & 0.75 & 0.25 & 0.05 & 2.295 \\
$\mathrm{~m} 25 \alpha 75 \beta 75$ & 25 & $40^{0}$ & 0.75 & 0.75 & 0.03 & 1.851 \\
\hline
\end{tabular}

Con la selección de los modelos se intentó muestrear distintas alturas y distintas combinaciones de parámetros donde, según los resultados de los análisis pushover, se pone más a prueba la metodología de diseño, pues en muchos de estos casos, a partir de esos resultados, se obtuvo que podrían presentarse fluencias en algunas vigas, como se puede inferir comparando los resúmenes presentados en las tablas 1 y 2 con los modelos indicados en la tabla 3.

Así, y dado que en teoría el mecanismo de diseño resiliente al 100\% es posible para todos los modelos de cinco niveles (tablas 1 y 2), se decidió probar a la combinación en teoría más desfavorable de parámetros de rigidez que fomenta la inelasticidad de las vigas del marco, y que es utilizar el parámetro $\alpha$ más grande $(\alpha=0.75)$, el parámetro $\beta$ más chico $(\beta=0.25)$ con el ángulo $\theta$ de $45^{0}$. Los modelos de 10 niveles se seleccionaron para cuando, según se indica sintéticamente en la tabla 2, se esperan fluencias inelásticas en vigas $(\alpha=0.75)$, y comparar con uno donde se espera una respuesta totalmente resiliente $(\alpha=0.25)$. Para los modelos de 15 niveles, se quería comparar la diferencia en la respuesta del ángulo de inclinación del contraviento cuando, conforme a los análisis pushover, se obtuvo que para $\alpha=0.75$ y $\beta=0.25$, para $\theta=45^{0}$ se deben esperar fluencias en vigas ante la acción de diseño cuando $k_{2} / k_{D D E}=0.05$ (tabla 2 ), mientras que para 
esa misma combinación de parámetros, se espera un comportamiento resiliente para $\theta=40^{0}$ (tabla 1). El comportamiento también debería ser resiliente para 15 niveles y cuando $\theta=40^{\circ}$ y $\alpha=\beta=0.50$ (tabla 1). En los modelos de 20 niveles se evaluaron combinaciones aceptables, aunque no $100 \%$ resilientes, considerando valores de $\alpha=0.50$ y $\beta=0.75$ que conforme a los análisis pushover, pueden liderar a algunas fluencias de vigas a la ductilidad objetivo de los disipadores para $\theta=45^{\circ}$ (tabla 2), pero a un comportamiento más satisfactorio cuando $\theta=40^{\circ}$ (tabla 1). Para los modelos de 25 niveles se evaluó un escenario crítico donde se aceptan muchas fluencias de vigas tanto para $\theta=45^{\circ}$ (cuando $k_{2} / k_{D D E}=0.05$, tabla 2) como para $\theta=40^{\circ}$ (cuando $k_{2} / k_{D D E}=0.03$, tabla 1 ). Con estos casos críticos de estudio se evalúa, de manera razonable, la robustez del método y los parámetros propuestos anteriormente (Hernández 2015, Tena y Hernández 2016 y 2017, TenaColunga y Hernández-Ramírez 2017), pues si no existen diferencias importantes aún para los casos donde no se espera un comportamiento $100 \%$ resiliente (sólo los disipadores trabajan inelásticamente), tampoco se presentaron en los casos en teoría más favorables.

\section{Registro de aceleración seleccionado para los análisis dinámicos no lineales}

Para realizar los análisis dinámicos no lineales, se seleccionó un registro de aceleración sintético generado por Pérez Rocha para la estación CO56 de la red acelerométrica del Valle de México (S56-EW), asociado a un sismo de subducción similar al del 19 de septiembre de $1985\left(M_{s}=8.1\right)$ y representativo de la zona de terreno blando de la ciudad de México (Roma Norte). El periodo dominante del sitio es $T_{s}=2.2 \mathrm{~s}$. El registro de aceleración sintético y sus correspondientes espectros de respuesta para dos amortiguamientos viscosos ( $\xi=2 \%$ y $\xi=5 \%$ ), se presentan en la figura 6 , así como el espectro de diseño elástico $(Q=1)$ según el Apéndice A de las NTCS-04 (2004).
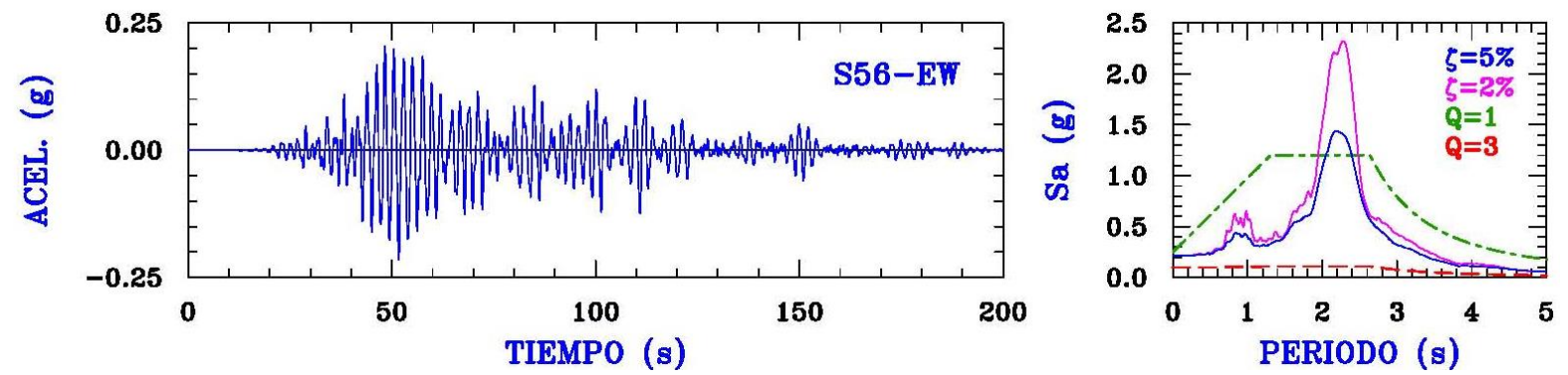

Figura 6. Registro de aceleración artificial para la estación 56 (S56-EW) para un sismo similar al del 19 de septiembre de $1985\left(\mathrm{M}_{\mathrm{s}}=8.1\right)$ y espectro de aceleraciones para $\xi=2 \%$ y $\xi=5 \%$, así como espectros de diseño elástico $(Q=1)$ e inelástico $(Q=3$ y $R=2.5)$ para el sitio CO56

El registro seleccionado supera en un 25\%, para un amortiguamiento viscoso equivalente del $5 \%$ $(\zeta=5 \%)$, la pseudoaceleración máxima de la meseta del espectro de diseño elástico $(Q=1)$ calculado conforme al Apéndice A de las NTCS-04 $(c=1.2 \mathrm{~g})$ y en $93 \%$ si se considera un amortiguamiento viscoso equivalente del $2 \%(\zeta=2 \%)$, que es más representativo de las estructuras de acero con conexiones soldadas.

Por lo tanto, es un acelerograma severo que pretende evaluar las reservas del sistema ante la acción de un sismo que rebase las acciones consideradas en el diseño, algo que desafortunadamente ya ocurrió en la Ciudad de México el 19 de septiembre de 1985, donde el espectro de respuesta de pseudoaceleración en el sitio SCT rebasó cuatro veces la ordenada máxima del espectro de diseño del reglamento del Distrito Federal de 1976, como se discute en Rosenblueth et al. (1989) y se ilustra gráficamente en Tena (2010).

Como referencia, también se presenta lo que sería un espectro de diseño conforme al Apéndice A de las NTCS-04 si se empleara $Q=3$ y $R=2.5$, que son parámetros globales de diseño promedio (por ejemplo, 
tablas 1 y 2) y prácticos que pudieran proponerse para su diseño conforme a esa norma para los modelos en estudio. Así, de este espectro identificado con $Q=3$, se obtiene que la pseudoaceleración de diseño en el intervalo de periodos fundamentales de vibrar elásticos en que se encuentran los modelos $(0.762 \mathrm{~s} \leq T \leq$ $2.295 \mathrm{~s})$ es $c=S_{a}=0.11 \mathrm{~g}, 10 \%$ mayor al valor considerado nominalmente en el diseño de todos los modelos $\left(\mathrm{c}=V / W_{l}=0.10\right)$. En otras palabras, los modelos en estudio estarían subdiseñados en un $10 \%$ con respecto al espectro reglamentario si se considera, además, que el amortiguamiento viscoso equivalente es del $5 \%$ $(\zeta=5 \%)$.

Los análisis dinámicos no lineales se realizaron considerando amortiguamientos viscosos tanto del $5 \%$ como del $2 \%$ por las siguientes razones. Es una práctica de diseño muy común emplear el espectro elástico para $\xi=5 \%$ y no corregir dicho espectro para un amortiguamiento menor, como debería ser el caso en estructuras de acero con conexiones soldadas. Bajo esas condiciones, los resultados de los análisis para el 5\% de amortiguamiento viscoso serían más representativos de la premisa general hecha en el diseño de los modelos y, por ende, su comparación debiera ser más próxima a lo obtenido con los análisis pushover. Sin embargo, dado que considerar $\xi=2 \%$ sería más realista (aunque conservador) del amortiguamiento viscoso inicial de estructuras de acero con conexiones soldadas, también es interesante evaluar cuáles serían las respuestas máximas y el patrón de fluencias que pudiesen presentarse cuando se subestiman las fuerzas de diseño ante una acción extrema, en este caso, tanto por la acción como por sobrestimar el amortiguamiento que es más representativo para ese tipo de estructuras.

\section{Modelo de 5 niveles}

En la figura 7 se presenta la comparativa de los mapeos de fluencias inelásticas obtenidas para el modelo m5 $\alpha 75 \beta 25$ (tabla 3), tanto del análisis pushover para la ductilidad objetivo de los disipadores de energía $\left(\mu_{d}\right)$, como de los análisis dinámicos no lineales para $\zeta=5 \%$ y $\zeta=2 \%$. En este caso se aprecia que existe una coincidencia importante en la ubicación espacial y en la magnitud relativa de los disipadores que fluyen entre el análisis pushover y los análisis dinámicos no lineales, aunque cabe destacar que las intensidades de las fluencias de los disipadores son menores en los análisis dinámicos no lineales que las obtenidas con el análisis pushover, como consecuencia que, para este modelo, dado su periodo fundamental elástico (tabla 3), de inicio se encuentra razonablemente alejado de respuestas resonantes (figura 6).

Esta observación se confirma con los resultados presentados en la figura 8, donde se reportan las demandas máximas de ductilidad de los disipadores de energía, las distorsiones de entrepiso máximas y los cortantes de entrepiso máximos y se aprecia que, en efecto, las curvas obtenidas del análisis pushover cubren satisfactoriamente bien a las obtenidas de los análisis dinámicos no lineales donde, como también era de esperarse, se obtienen mayores demandas cuando se considera $\zeta=2 \%$, que cuando se considera $\zeta=5 \%$. También se aprecia que los disipadores de energía desarrollan demandas de ductilidad superiores a seis aún para distorsiones de entrepiso inferiores al $1 \%$. Se comprueba que el mecanismo último obtenido ante la acción dinámica extrema de diseño para el sitio considerado es $100 \%$ resiliente. 


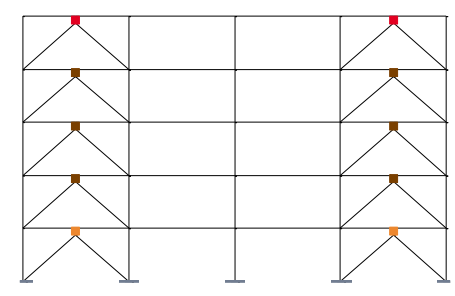

a) Pushover

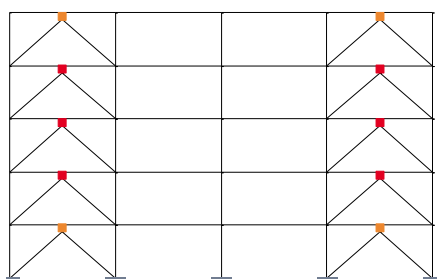

b) $\mathrm{S} 56-\mathrm{EW}, \zeta=5 \%$

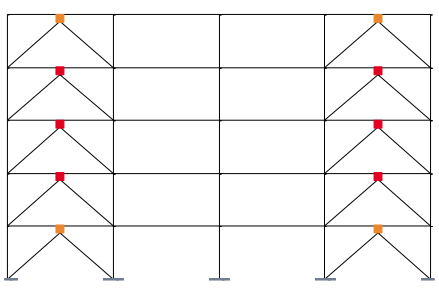

c) $\mathrm{S} 56-\mathrm{EW}, \zeta=2 \%$

Figura 7. Comparativa de los mapeos de fluencias inelásticas para el modelo m5 $\alpha 75 \beta 25\left(\theta=45^{0}\right.$, $\mathrm{k}_{2} / \mathrm{k}_{\mathrm{DDE}}=0.05$ )
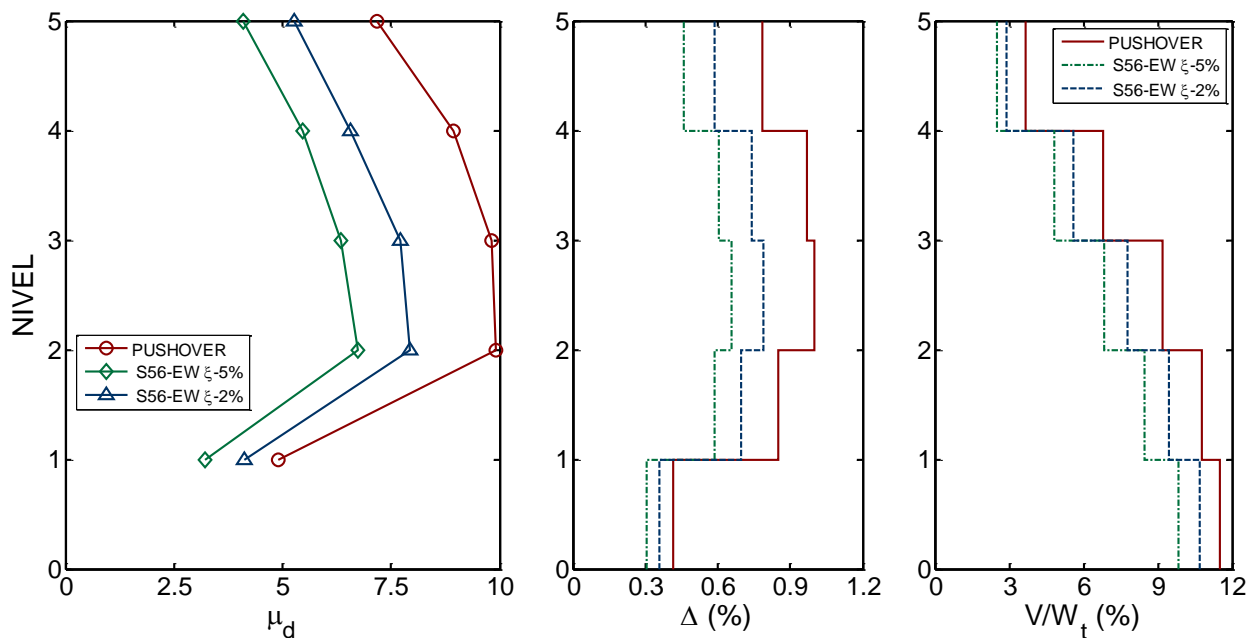

Figura 8. Comparativa de demandas de ductilidad $\mu_{d}$ de los disipadores de energía, distorsiones de entrepiso máximas y fuerzas cortantes máximas en los entrepisos, para el modelo m5 $\alpha 75 \beta 25\left(\theta=45^{0}\right.$, $\left.\mathrm{k}_{2} / \mathrm{k}_{\mathrm{DDE}}=0.05\right)$

Los resultados obtenidos permiten también a uno ilustrar y comentar aspectos que son muy importantes y que se deben tomar en cuenta en el diseño sismorresistente de estructuras en general, pues no sólo se presentan en estructuras con disipadores de energía: a) la conveniencia de que el periodo fundamental elástico de la estructura diseñada se encuentre muy alejado del periodo del sitio $\left(T_{s}\right)$, para evitar respuestas resonantes indeseables, b) cuando se consideran valores altos de reducción por ductilidad $(Q)$ en el diseño sísmico, no obstante que el periodo fundamental de la estructura se encuentre muy alejado del periodo del sitio, se presentarán irremediablemente respuestas inelásticas de importancia en la estructura ante la acción considerada para el sitio (en este caso, en término de la ductilidad de los disipadores). Para el modelo en estudio, el diseño obtenido resultó ser $100 \%$ resiliente y también favorecido porque la estructura tiene un periodo fundamental de vibrar razonablemente alejado de la franja resonante, lo que un diseñador experto y realmente interesado en proteger a las personas y a su patrimonio, debería buscar siempre, en la medida de las limitantes generales del proyecto de diseño que le fue encomendado.

\section{Modelos de 10 niveles}

En la figura 9 se presenta la comparativa de los mapeos de fluencias inelásticas obtenidas para el modelo m10 $253 \beta 25$ (tabla 3). Conforme a los resultados del análisis pushover, el mecanismo último esperado ante la acción sísmica de diseño debería ser $100 \%$ resiliente, con fluencias exclusivas en los disipadores (figura 9a). Los mapeos de fluencia obtenidos en los análisis dinámicos no lineales concuerdan razonablemente bien con los del análisis pushover tanto para $\zeta=5 \%$ (figura $9 \mathrm{~b}$ ) como para $\zeta=2 \%$ (figura 9c). 
Nuevamente, cabe señalar que las intensidades de las fluencias de los disipadores son menores en los análisis dinámicos no lineales que las obtenidas con el análisis pushover, como consecuencia que, para este modelo, dado su periodo fundamental elástico $(\mathrm{T}=1.24 \mathrm{~s}$, tabla 3$)$, se encuentra razonablemente alejado de respuestas resonantes, aunque ya en la rama francamente ascendente del espectro (figura 6).

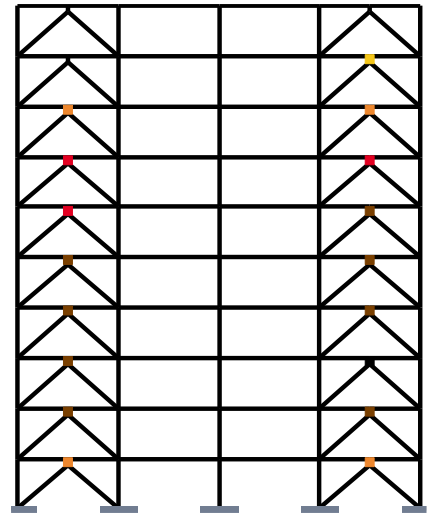

a) Pushover

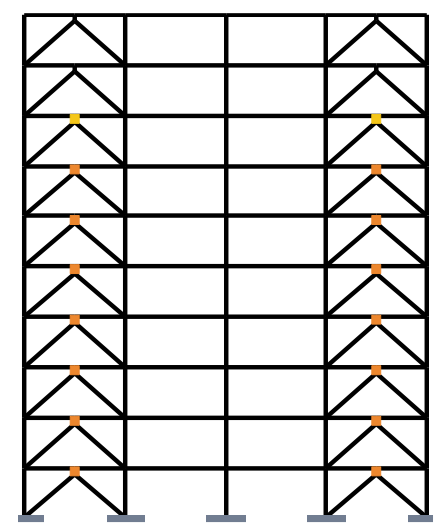

b) S56-EW $\xi=5 \%$

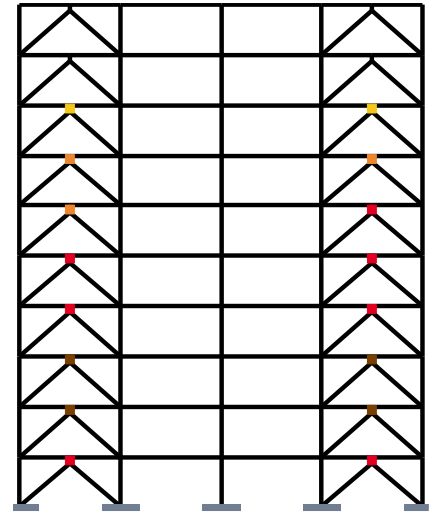

c) S56-EW $\xi=2 \%$

Figura 9. Comparativa de los mapeos de fluencias inelásticas para el modelo m10 $\alpha 25 \beta 25\left(\theta=45^{0}\right.$, $\mathrm{k}_{2} / \mathrm{k}_{\mathrm{DDE}}=0$ )

Esta observación se confirma nuevamente con los resultados de las demandas máximas de ductilidad de los disipadores de energía, las distorsiones de entrepiso máximas y los cortantes de entrepiso máximos que se presentan en la figura 10, donde se comprueba que las curvas obtenidas del análisis pushover cubren satisfactoriamente bien a las obtenidas de los análisis dinámicos no lineales para $\zeta=5 \%$ y aún para $\zeta=2 \%$, a excepción de las demandas máximas para el primer nivel. Nuevamente, los disipadores de energía desarrollan demandas de ductilidad altas para distorsiones de entrepiso inferiores al 1\%. El mecanismo obtenido ante la acción dinámica extrema es nuevamente 100\% resiliente.
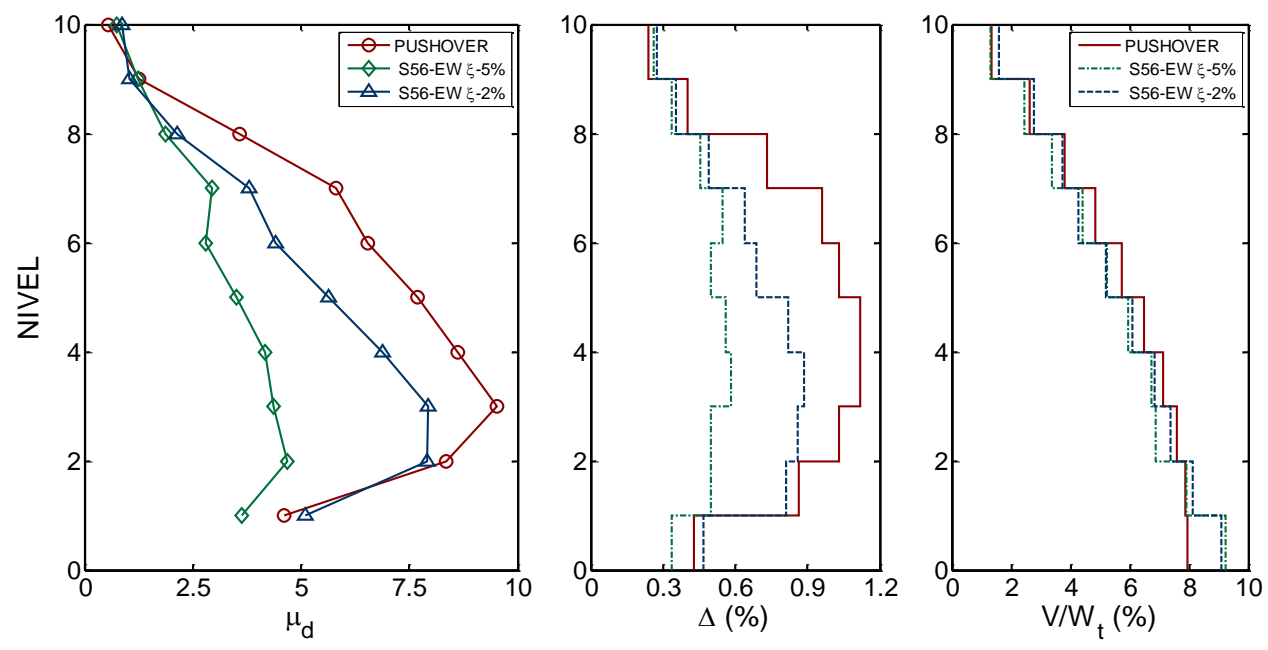

Figura 10. Comparativa de demandas de ductilidad $\mu_{d}$ de los disipadores de energía, distorsiones de entrepiso máximas y fuerzas cortantes máximas en los entrepisos, para el modelo m10 $\alpha 25 \beta 25\left(\theta=45^{0}\right.$, $\mathrm{k}_{2} / \mathrm{k}_{\mathrm{DDE}}=0$ ) 
En las figuras 11 a 16 se presentan los resultados de tres modelos que se diseñaron con los mismos balances de rigideces, $\alpha=0.75$ y $\beta=0.25$, pero donde las secciones de los elementos resistentes del marco varían un poco como resultado que se supusieron distintas pendientes posteriores a la fluencia de los disipadores, $\mathrm{k}_{2} / \mathrm{k}_{\mathrm{DDE}}=0$ (elastoplástico perfecto, figuras $11 \mathrm{y} 12$ ), $\mathrm{k}_{2} / \mathrm{k}_{\mathrm{DDE}}=0.03$ (figuras $13 \mathrm{y} 14$ ) y $\mathrm{k}_{2} / \mathrm{k}_{\mathrm{DDE}}=0.05$ (figuras 15 y 16), lo cual se refleja también en los periodos fundamentales de vibración reportados en la tabla 3. De acuerdo con los análisis pushover de cada modelo, si se llevan a la ductilidad objetivo $\mu_{d}=10$ de los disipadores críticos, se espera la fluencia incipiente en algunas vigas, presentándose relativamente más para el caso elastoplástico perfecto (figura 11a), que cuando se diseñan para pendientes posteriores a la fluencia de 3\% (figura 13a) y 5\% (figura 15a).

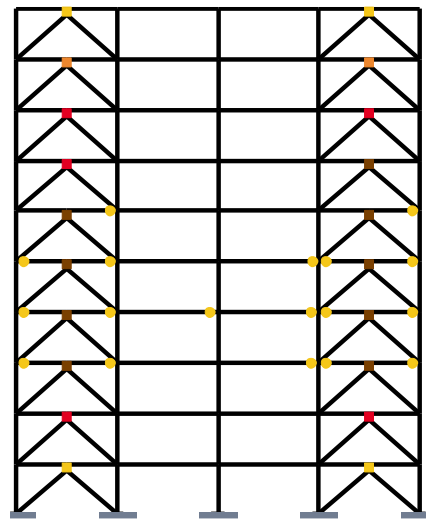

a) Pushover

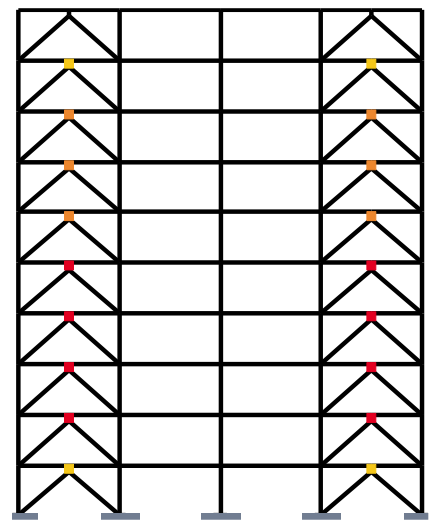

b) S56-EW $\xi=5 \%$

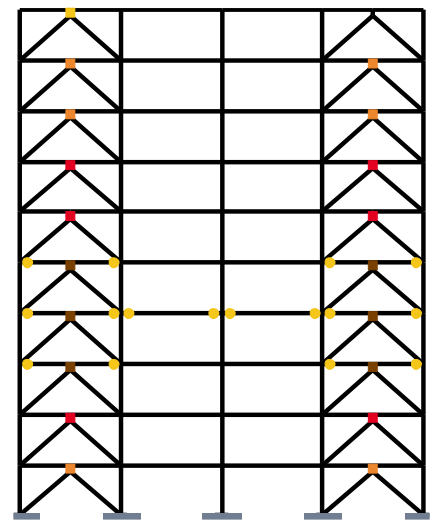

c) S56-EW $\xi=2 \%$

Figura 11. Comparativa de los mapeos de fluencias inelásticas para el modelo m10 $\alpha 75 \beta 25-1\left(\theta=45^{0}\right.$,

$$
\mathrm{k}_{2} / \mathrm{k}_{\mathrm{DDE}}=0 \text { ) }
$$

Cuando se realizan los análisis dinámicos no lineales ante la acción del registro de aceleración S56EW y suponiendo un amortiguamiento viscoso equivalente $\zeta=5 \%$, congruente con lo supuesto en el diseño, se aprecia que para el caso elastoplástico (figura 11b) el mapeo de fluencias es muy similar y, de hecho, más resiliente que el del análisis pushover (figura 11a), lo que se confirma en la figura 12, donde las curvas obtenidas con el análisis pushover a la ductilidad objetivo de los disipadores críticos envuelven las respuestas máximas obtenidas del análisis dinámico no lineal.

Cuando el diseño se hace suponiendo $\mathrm{k}_{2} / \mathrm{k}_{\mathrm{DDE}}=0.03$ para los disipadores, el mapeo de fluencias ante el registro S56-EW (figura 13b) es similar al del análisis pushover (figura 13a), pero con unas pocas fluencias más de extremos de vigas (tres en total) en la zona esperada (más demandada). Nuevamente, en la figura 14 se observa que las curvas obtenidas del análisis pushover envuelven a las obtenidas considerando $\zeta=5 \%$, completamente en cuanto a ductilidades máximas desarrolladas por los disipadores y distorsiones máximas de entrepiso, y casi en su totalidad para cortantes, donde se aprecia que es precisamente a partir del cuarto piso dónde la curva para $\zeta=5 \%$ lidera a mayores cortantes que la obtenida con el análisis pushover, y esto explica el por qué existen fluencias adicionales de tres extremos de viga en ese entrepiso (figura 13b). 

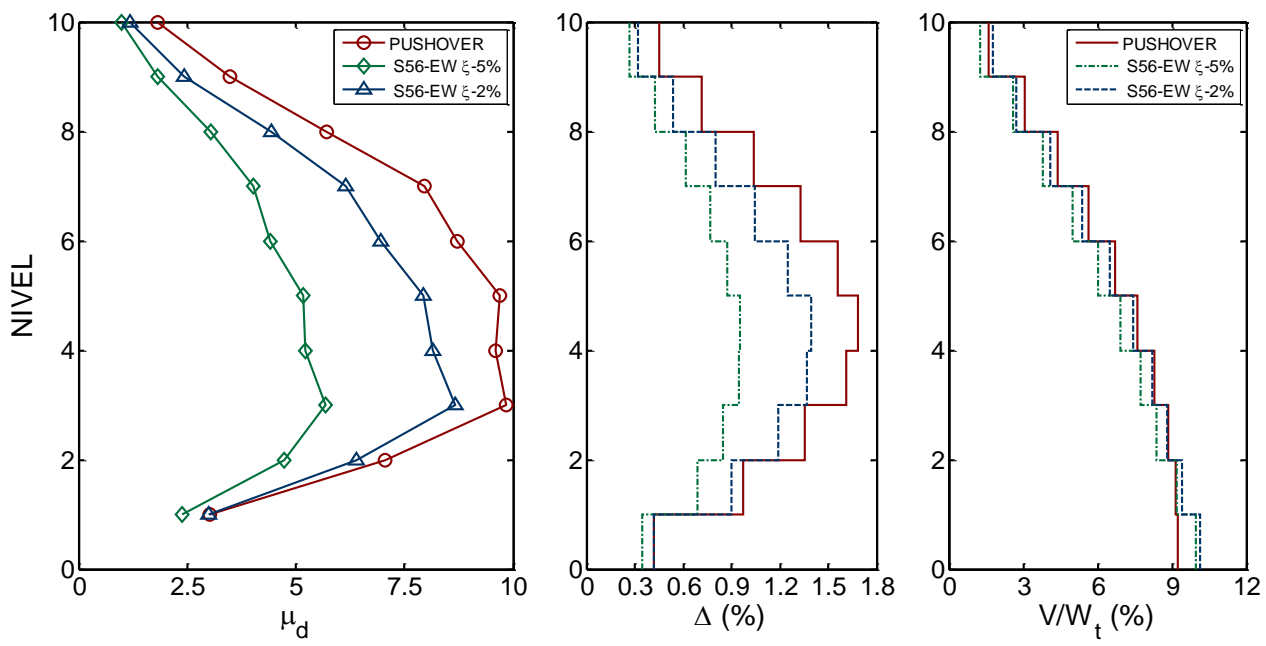

Figura 12. Comparativa de demandas de ductilidad $\mu_{d}$ de los disipadores de energía, distorsiones de entrepiso máximas y fuerzas cortantes máximas en los entrepisos, para el modelo m10 $\alpha 75 \beta 25-1\left(\theta=45^{\circ}\right.$, $\left.\mathrm{k}_{2} / \mathrm{k}_{\mathrm{DDE}}=0\right)$

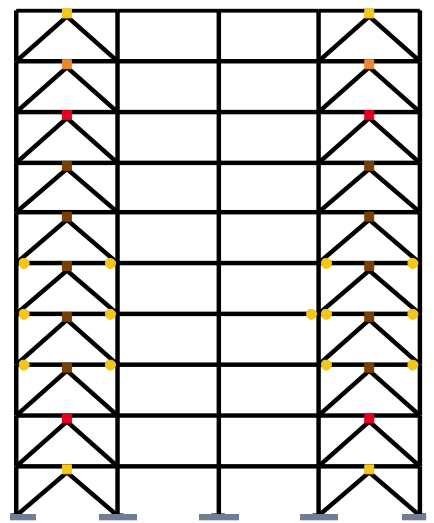

a) Pushover

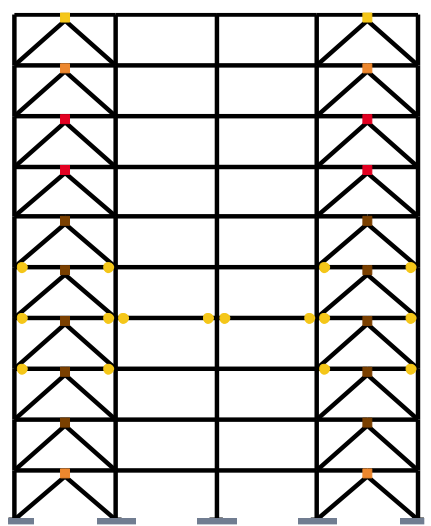

b) S56-EW $\xi=5 \%$

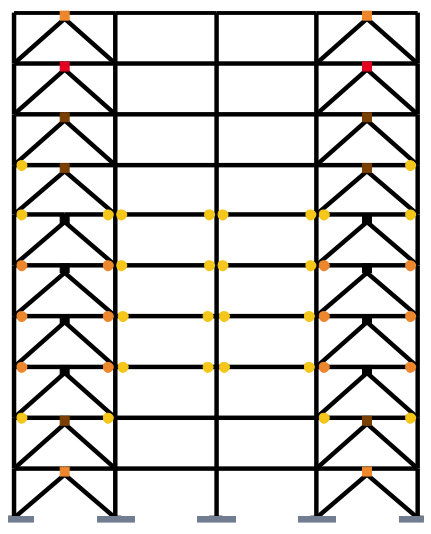

c) $\mathrm{S} 56-\mathrm{EW} \xi=2 \%$

Figura 13. Comparativa de los mapeos de fluencias inelásticas para el modelo m10 $\alpha 75 \beta 25-2\left(\theta=45^{0}\right.$, $\mathrm{k}_{2} / \mathrm{k}_{\mathrm{DDE}}=0.03$ )

Cuando en el diseño se considera $\mathrm{k}_{2} / \mathrm{k}_{\mathrm{DDE}}=0.05$ para los disipadores, el mapeo de fluencias ante el registro S56-EW (figura 15b) sigue siendo similar al del análisis pushover (figura 15a), pero con más fluencias en vigas en la zona esperada, en función de las demandas de ductilidad de los disipadores. Esto sucede como consecuencia que, como se observa en la figura 16, las curvas obtenidas del análisis dinámico no lineal para $\zeta=5 \%$ superan ligeramente a las del análisis pushover en cuanto a distorsiones de entrepiso, pero ligeramente más en cuanto a las ductilidades desarrolladas por los disipadores, por lo que, al responder con una pendiente posterior a la fluencia distinta de cero, esto lleva a que se demanden mayores fuerzas cortantes de entrepiso y es lo que favorece que fluyan más vigas en los niveles más demandados (niveles 3 , 4 y 5 , figura $15 b)$. 

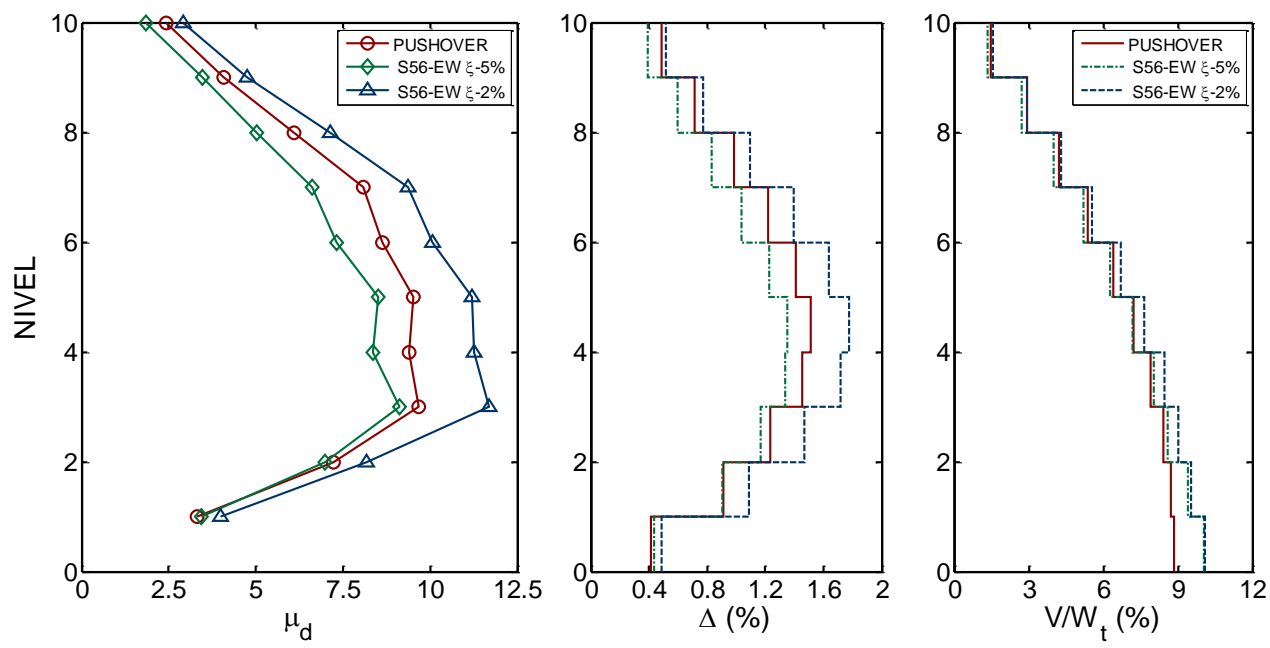

Figura 14. Comparativa de demandas de ductilidad $\mu_{d}$ de los disipadores de energía, distorsiones de entrepiso máximas y fuerzas cortantes máximas en los entrepisos, para el modelo m10 $\alpha 75 \beta 25-2\left(\theta=45^{0}\right.$, $\mathrm{k}_{2} / \mathrm{k}_{\mathrm{DDE}}=0.03$ )

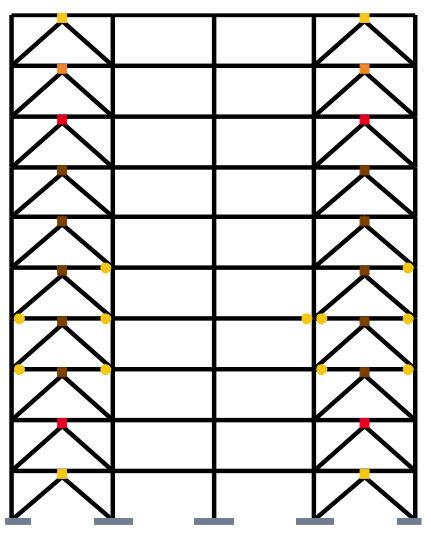

a) Pushover

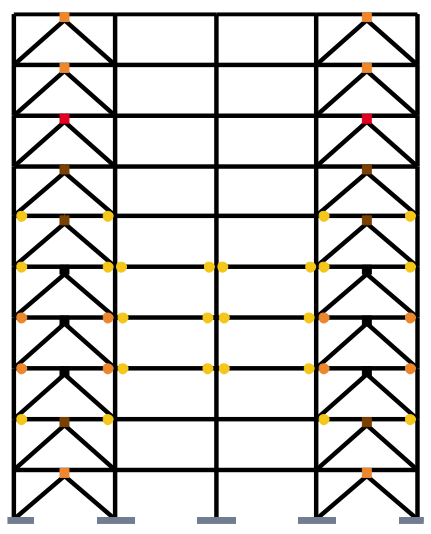

b) S56-EW $\xi=5 \%$

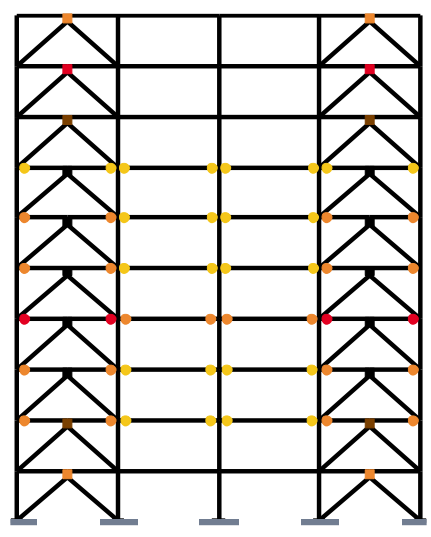

c) S56-EW $\xi=2 \%$

Figura 15. Comparativa de los mapeos de fluencias inelásticas para el modelo m10 $\alpha 75 \beta 25-3\left(\theta=45^{0}\right.$, $\mathrm{k}_{2} / \mathrm{k}_{\mathrm{DDE}}=0.05$ )

Los análisis dinámicos no lineales ante la acción del registro de aceleración S56-EW y suponiendo un amortiguamiento viscoso equivalente $\zeta=2 \%$ representan un escenario donde se rebasan las acciones de diseño, ya sea porque: a) en el diseño se supuso un amortiguamiento viscoso equivalente superior al más representativo del sistema considerado, avalado con lo que permiten los reglamentos $(\zeta=5 \%$ considerado para todos los sistemas estructurales) o, b) la acción extrema superó al espectro de diseño. De esta manera, está dentro de lo esperado que, para los modelos diseñados considerando que los disipadores tienen una pendiente posterior a la fluencia distinta de cero, las respuestas dinámicas máximas rebasen a las obtenidas en el análisis pushover, tanto cuando $\mathrm{k}_{2} / \mathrm{k}_{\mathrm{DDE}}=0.03$ (figura 14), como para $\mathrm{k}_{2} / \mathrm{k}_{\mathrm{DDE}}=0.05$ (figura 16). Sin embargo, para el caso elastoplástico perfecto (figura 12), las curvas de los análisis pushover siguieron envolviendo a las obtenidas para $\zeta=2 \%$, como consecuencia, en parte, de que el proceso de diseño lideró a una estructura ligeramente más rígida $(\mathrm{T}=1.30 \mathrm{~s}$, tabla 3$)$, que los diseños obtenidos cuando se considera que $\mathrm{k}_{2} / \mathrm{k}_{\mathrm{DDE}} \neq 0$, lo que llevó a este modelo a demandas menores. Los mapeos de fluencia obtenidos para $\zeta=2 \%$ (figuras $11 \mathrm{c}, 13 \mathrm{c}$ y 15c) son congruentes con la metodología de diseño por capacidad propuesta, en cuanto a que, si la resistencia de diseño considerada es rebasada por la acción extrema, la siguiente línea de defensa inelástica después de los disipadores de energía, que se diseñan para ser los fusibles estructurales, la 
constituyen las vigas de los marcos, y su fluencia debe ser incipiente y, cuando más, moderada. También cabe señalar que cuando se rebasa la ductilidad objetivo de diseño de los disipadores, se deben esperar más fluencias y de mayor magnitud (mayor daño) en los marcos a medida que la pendiente posterior a la fluencia de los disipadores $\left(\mathrm{k}_{2} / \mathrm{k}_{\mathrm{DDE}}\right)$ aumenta, como consecuencia que estarían transmitiendo fuerzas cortantes mayores al marco a medida que continúan aumentando su ductilidad que las que fueron consideradas en su diseño.
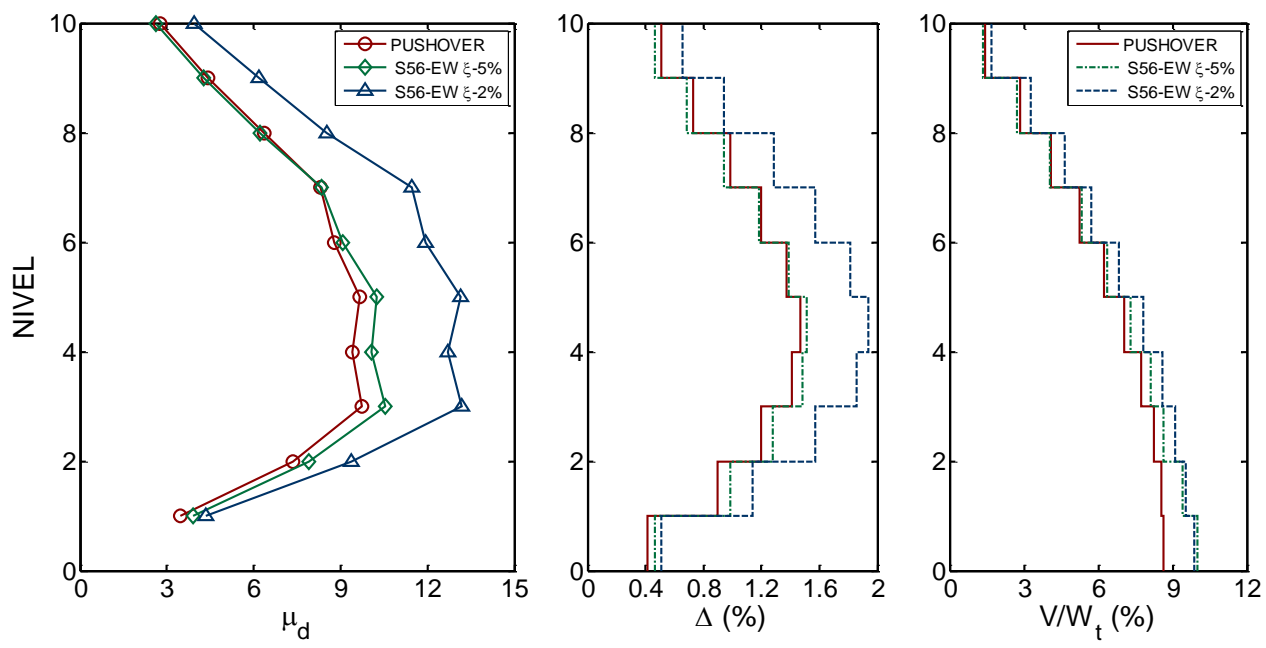

Figura 16. Comparativa de demandas de ductilidad $\mu_{d}$ de los disipadores de energía, distorsiones de entrepiso máximas y fuerzas cortantes máximas en los entrepisos, para el modelo m10 $\alpha 75 \beta 25-3\left(\theta=45^{0}\right.$, $\mathrm{k}_{2} / \mathrm{k}_{\mathrm{DDE}}=0.05$ )

\section{Modelos de 15 niveles}

En las figuras 17 a 20 se presentan los resultados de dos modelos que se diseñaron con los mismos balances de rigideces, $\alpha=0.75$ y $\beta=0.25$ y pendientes posteriores a la fluencia de los disipadores, $\mathrm{k}_{2} / \mathrm{k}_{\mathrm{DDE}}=0.05$, pero donde las secciones de los elementos resistentes del marco varían bastante como resultado que las alturas de entrepiso son distintas y, por ende, el ángulo de inclinación de los contravientos con respecto al plano horizontal, $\theta$. Como se aprecia en la tabla 3 , esto redunda en que los periodos fundamentales de vibración sean bastante distintos, mayor para el marco más esbelto $\left(\theta=45^{0}\right)$, pero ambos en la rama ascendente del espectro donde, abusando de un diseño dúctil, se debe esperar una respuesta dinámica resonante, como se puede demostrar con un espectro de demanda de ductilidad que tome en cuenta las características de estos sistemas, pues en el intervalo no lineal, el periodo crítico para obtener respuestas resonantes es inferior al periodo fundamental elástico que define la resonancia, y se aleja más de éste a medida que su resistencia lateral de fluencia es menor y depende también de si el sistema es dúctil o se degrada en rigidez y resistencia, como se ha ilustrado en trabajos previos (Tena 1997 y 1998b, Tena-Colunga 2001) y se ilustra más adelante.

De acuerdo con los análisis pushover de cada modelo, si se llevan a la ductilidad objetivo $\mu_{d}$ de los disipadores críticos, se espera la fluencia incipiente en algunas vigas para el modelo más flexible $\left(\theta=45^{0}\right.$, figura 17a) y un diseño resiliente al $100 \%$ para $\theta=40^{\circ}$ (figura 19a).

Cuando se realizan los análisis dinámicos no lineales ante la acción del registro de aceleración S56EW y suponiendo un amortiguamiento viscoso equivalente $\zeta=5 \%$, se aprecia que para el modelo más flexible $\left(\theta=45^{\circ}\right)$ se presenta una respuesta dentro de lo esperado en cuanto a magnitud y ubicación de las 
fluencias (figura 17b) con respecto a los resultados obtenidos del análisis pushover. Lo anterior se confirma en las curvas de respuestas máximas de las ductilidades de los disipadores y de las distorsiones de entrepiso máximas, que quedan prácticamente envueltas por las obtenidas en el análisis pushover, excepto para los dos primeros niveles (figura 18). La ligera diferencia en las fluencias de las vigas se debe a que la excitación dinámica alterna sentidos (hay fluencia en vigas en ambos lados) y a que los cortantes de entrepiso máximos son ligeramente mayores (figura 18), además de una ligera participación multimodal.

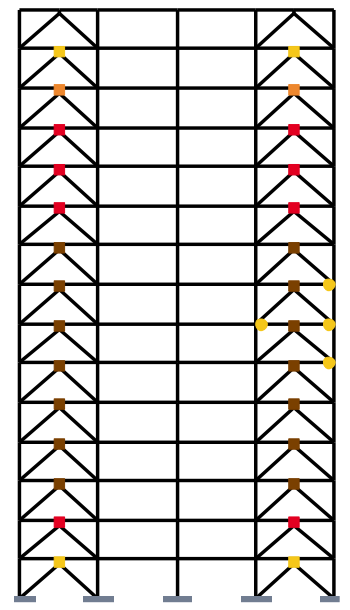

a) Pushover

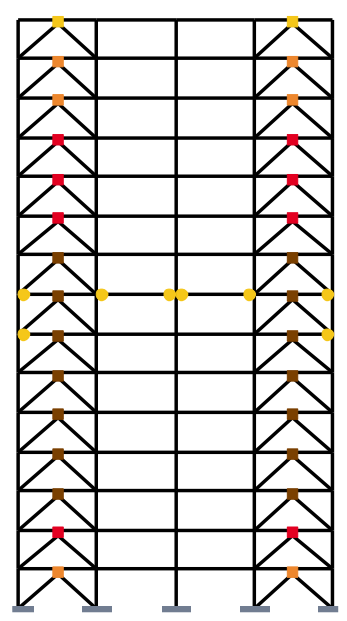

b) S56-EW $\xi=5 \%$

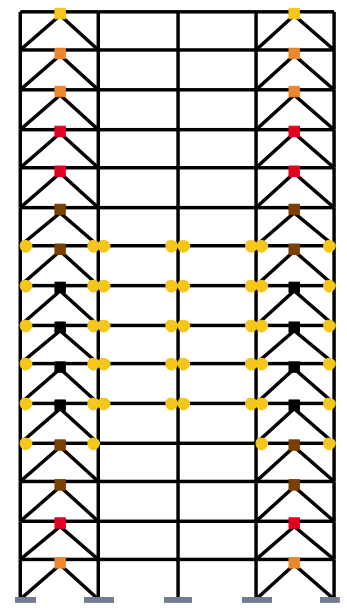

c) S56-EW $\xi=2 \%$

Figura 17. Comparativa de los mapeos de fluencias inelásticas para el modelo m15 $\alpha 75 \beta 25-1\left(\theta=45^{0}\right.$, $\mathrm{k}_{2} / \mathrm{k}_{\mathrm{DDE}}=0.05$ )
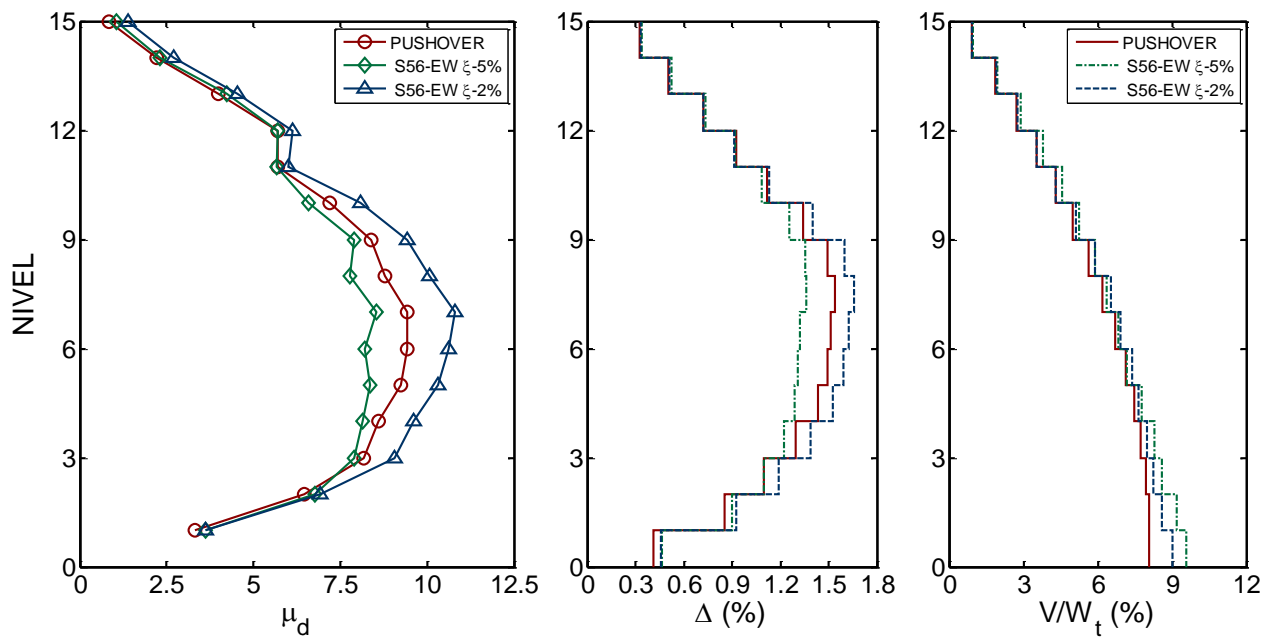

Figura 18. Comparativa de demandas de ductilidad $\mu_{d}$ de los disipadores de energía, distorsiones de entrepiso máximas y fuerzas cortantes máximas en los entrepisos, para el modelo m15 $\alpha 75 \beta 25-1\left(\theta=45^{0}\right.$, $\mathrm{k}_{2} / \mathrm{k}_{\mathrm{DDE}}=0.05$ )

Para el modelo que resultó un poco más rígido $\left(\theta=40^{\circ}\right)$, se presentan varias fluencias incipientes en vigas (figura 19b), aún dentro de tolerable si se toma en cuenta que esto se debe a que las demandas de ductilidad de los disipadores rebasaron las supuestas en su diseño (figura 20), por lo que se desarrollaron mayores distorsiones y cortantes de entrepiso (figura 20). Esto se debe a que la respuesta del sistema fue francamente resonante, como se ilustra y discute a continuación empleando el concepto de espectros de demandas de ductilidad (Tena 1997 y 1998b, Tena-Colunga 2001). 


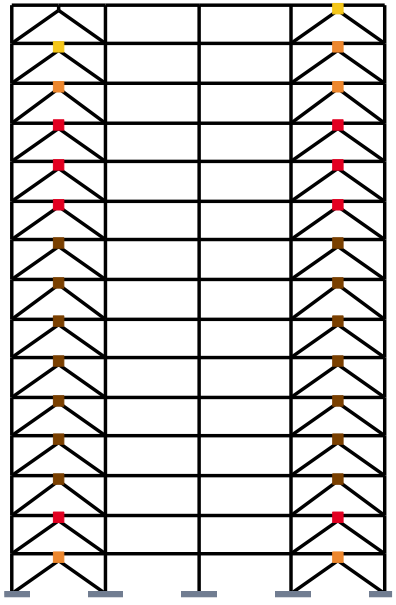

a) Pushover

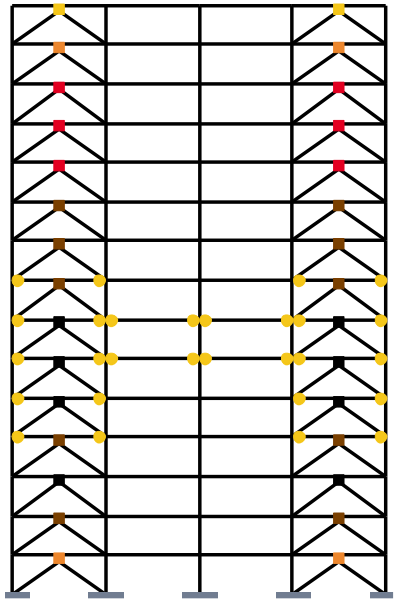

b) S56-EW $\xi=5 \%$

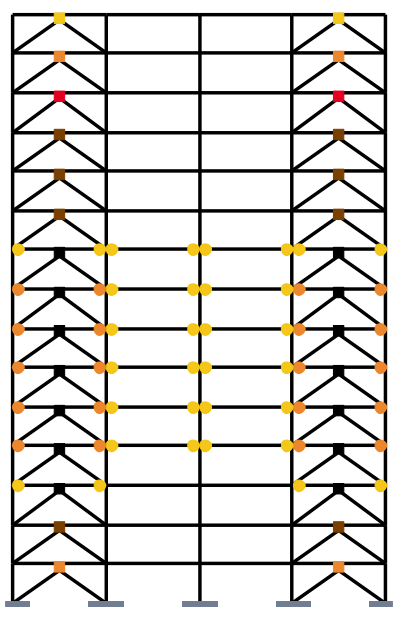

c) $\mathrm{S} 56-\mathrm{EW} \xi=2 \%$

Figura 19. Comparativa de los mapeos de fluencias inelásticas para el modelo m15 $\alpha 75 \beta 25-2\left(\theta=40^{\circ}\right.$, $\mathrm{k}_{2} / \mathrm{k}_{\mathrm{DDE}}=0.05$ )
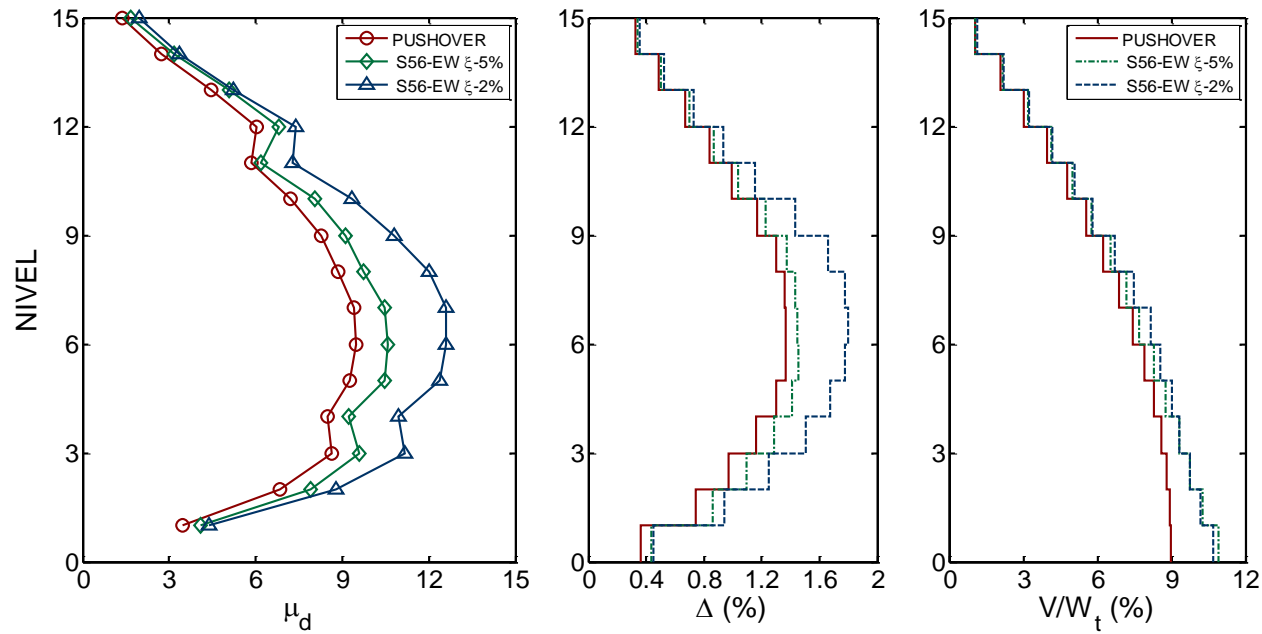

Figura 20. Comparativa de demandas de ductilidad $\mu_{d}$ de los disipadores de energía, distorsiones de entrepiso máximas y fuerzas cortantes máximas en los entrepisos, para el modelo m15 $\alpha 75 \beta 25-2\left(\theta=40^{0}\right.$,

$$
\mathrm{k}_{2} / \mathrm{k}_{\mathrm{DDE}}=0.05 \text { ) }
$$

Para explicar mejor el por qué para el modelo más rígido (m15 $\left.\alpha 75 \beta 25-2, \theta=40^{0}, \mathrm{~T}=1.547 \mathrm{~s}\right)$ se obtuvieron comparativamente mayores demandas que para el modelo más flexible $\left(\mathrm{m} 15 \alpha 75 \beta 25-1, \theta=45^{0}\right.$, $\mathrm{T}=1.842 \mathrm{~s}$ ), nos apoyaremos con los resultados mostrados en la figura 21 . Utilizando exclusivamente conceptos de dinámica estructural elástica, y con base exclusivamente en el espectro elástico de respuesta para $\zeta=5 \%$, debiera esperarse que el modelo $\mathrm{m} 15 \alpha 75 \beta 25-2\left(\theta=40^{\circ}\right)$, cuya respuesta elástica para su periodo fundamental de vibración se indica con un cuadro azul en la figura 21, al estar más alejado del periodo resonante del espectro elástico que el modelo $\mathrm{m} 15 \alpha 75 \beta 25-1\left(\theta=45^{0}\right)$, cuya respuesta elástica se indica con un círculo rojo, debiera también tener una respuesta más favorable en el intervalo de comportamiento no lineal (es decir, una inelasticidad comparativamente menor). 
Esto no necesariamente resulta cierto en sistemas altamente no lineales, pues las demandas de ductilidad que desarrollan los sistemas dependen, entre muchos otros parámetros, de su fuerza a la fluencia, del tipo de comportamiento histerético (bilineal con endurecimiento, elastoplástico, degradante en rigidez, degradante en resistencia, etc.), como se discute en trabajos previos (Tena 1997 y 1998b, Tena-Colunga 2001). Por ello se calcularon los espectros de demanda de ductilidad para estos dos modelos, con base en las curvas primarias globales que se definieron a partir del análisis pushover. De esta manera, la curvas bilineales resultantes tuvieron los siguientes parámetros que definen al modelo bilineal global: a) para el modelo m15 $\alpha 75 \beta 25-1\left(\theta=45^{0}\right)$, la resistencia normalizada a la fluencia fue $\mathrm{V}_{\mathrm{y}} / \mathrm{W}_{\mathrm{t}}=0.195$ y la pendiente posterior a la fluencia normalizada con respecto a la rigidez elástica fue $\mathrm{K}_{2} / \mathrm{K}_{\mathrm{e}}=0.24$, b) para el modelo m15 $\alpha 75 \beta 25-2\left(\theta=40^{0}\right)$, los parámetros globales fueron $\mathrm{V}_{\mathrm{y}} / \mathrm{W}_{\mathrm{t}}=0.191$ y $\mathrm{K}_{2} / \mathrm{K}_{\mathrm{e}}=0.30$. Usando estos parámetros globales, se trazaron los espectros de demandas de ductilidad que se muestran también en la figura 21, y en ellos se aprecia que, para el periodo elástico inicial de los modelos, en efecto, la demanda máxima de ductilidad del sistema inicialmente más rígido (modelo m15 $\alpha 75 \beta 25-2, \theta=40^{\circ}$, indicado con un cuadro azul que $\mu=5.24$ para $\mathrm{T}=1.547 \mathrm{~s}$ ), son mayores que para el modelo inicialmente más flexible (modelo m15 $\alpha 75 \beta 25-1, \theta=45^{0}$, señalando con un cuadro rojo que $\mu=3.07$ para $\mathrm{T}=1.842 \mathrm{~s}$ ). De los espectros de demanda de ductilidad se aprecia también que, para las resistencias de fluencia normalizadas consideradas ( $19.1 \%$ y $19.5 \%$ del peso total de la estructura), y para las pendientes posteriores a la fluencia consideradas (24\% y $30 \%$ de la elástica), las respuestas francamente resonantes en sistemas inelásticos de estas características se producen cuando los periodos fundamentales elásticos de los sistemas son $\mathrm{T}=1.37 \mathrm{~s}$ (modelo m15 $\alpha 75 \beta 25-1, \theta=45^{\circ}$ ) y $\mathrm{T}=1.45 \mathrm{~s}$ (modelo $\mathrm{m} 15 \alpha 75 \beta 25-2, \theta=40^{\circ}$ ).
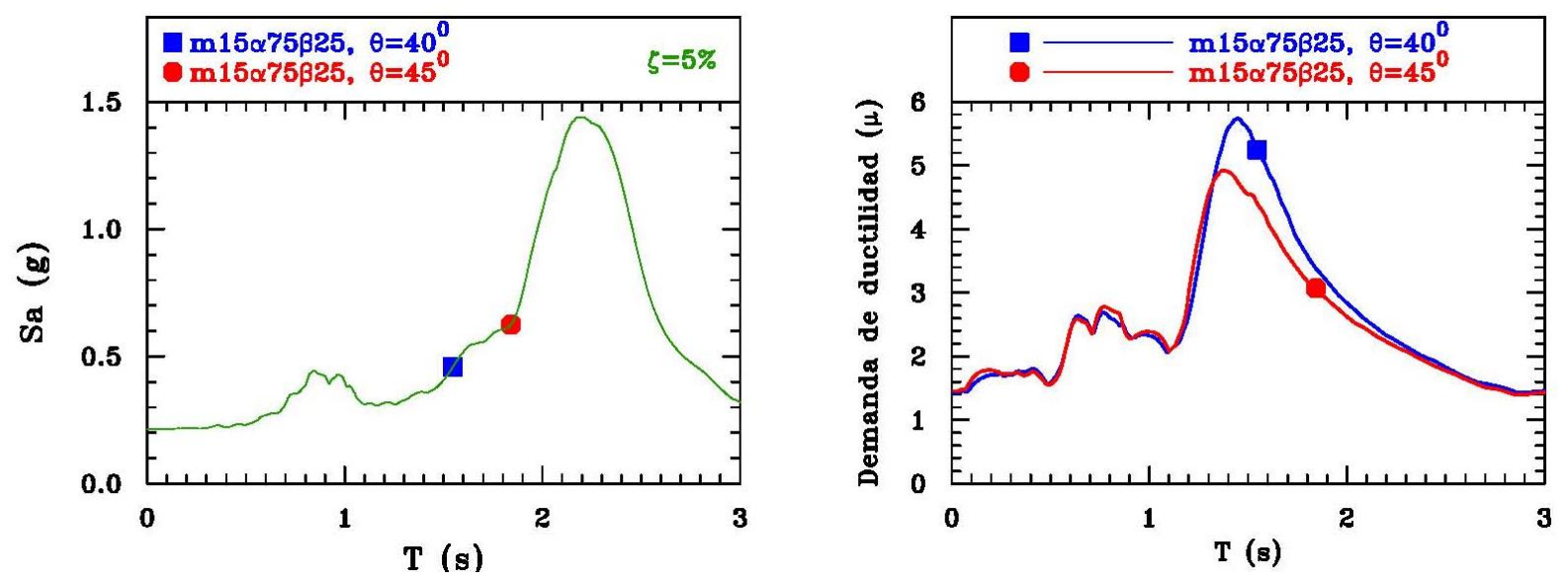

Figura 21. Espectros de respuesta elástico y de demanda de ductilidad para los modelos m $15 \alpha 75 \beta 25$ para el registro de aceleración S56-EW

Los autores consideran muy importante ilustrar este aspecto, porque para sistemas no lineales, las respuestas resonantes se producen para periodos fundamentales elásticos inferiores al periodo asociado a la resonancia elástica, y tienden a alejarse más de éste conforme más se reduce la resistencia normalizada de fluencia, cuando el resto de las características que definen al modelo histerético permanecen invariables. Es por ello que abusar de la reducción de fuerzas de diseño por concepto de ductilidad, considerando ductilidades muy grandes, sin tomar en cuenta cómo afecta la respuesta dinámica del sistema estructural en estudio, es una práctica muy peligrosa en el diseño sismorresistente de estructuras, que puede liderar a muchas estructuras a respuestas indeseables, incluso a un colapso no contemplado.

En las figuras 22 y 23 se presentan los resultados de un modelo donde, conforme al análisis pushover, se espera una respuesta totalmente resiliente cuando los balances de rigideces son $\alpha=0.5$ y $\beta=0.5$ y la pendiente posterior a la fluencia de los disipadores es $\mathrm{k}_{2} / \mathrm{k}_{\mathrm{DDE}}=0.03$ cuando $\theta=40^{0}$ (figura 22a). Cuando se 
realizan los análisis dinámicos no lineales ante la acción del registro de aceleración S56-EW y suponiendo un amortiguamiento viscoso equivalente $\zeta=5 \%$, se tiene una concordancia plena en el mapeo de fluencias para este sistema (figura 22b), el cual tiene un periodo fundamental elástico $\mathrm{T}=1.55 \mathrm{~s}$ (tabla 3 ). De igual manera, sus respuestas máximas de ductilidad y de distorsión son bien envueltas por el análisis pushover (figura 23).

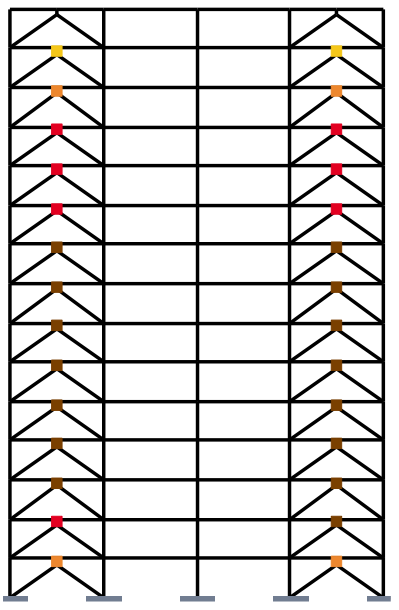

a) Pushover

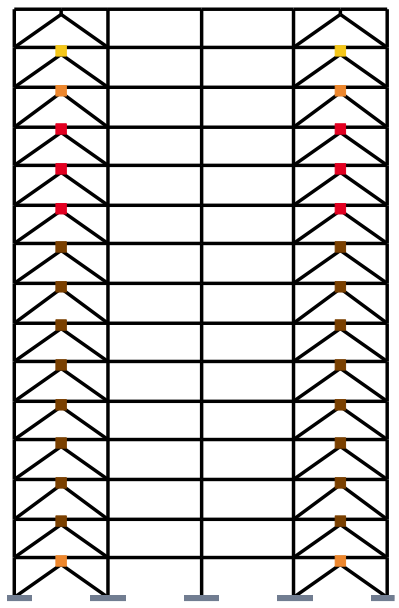

b) S56-EW $\xi=5 \%$

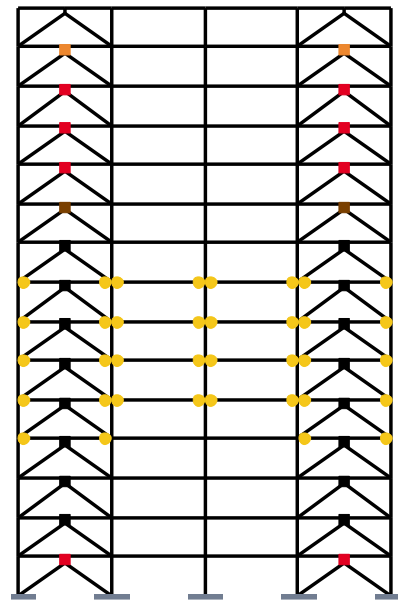

c) S56-EW $\xi=2 \%$

Figura 22. Comparativa de los mapeos de fluencias inelásticas para el modelo m15 $\alpha 50 \beta 50\left(\theta=40^{0}\right.$, $\mathrm{k}_{2} / \mathrm{k}_{\mathrm{DDE}}=0.03$ )
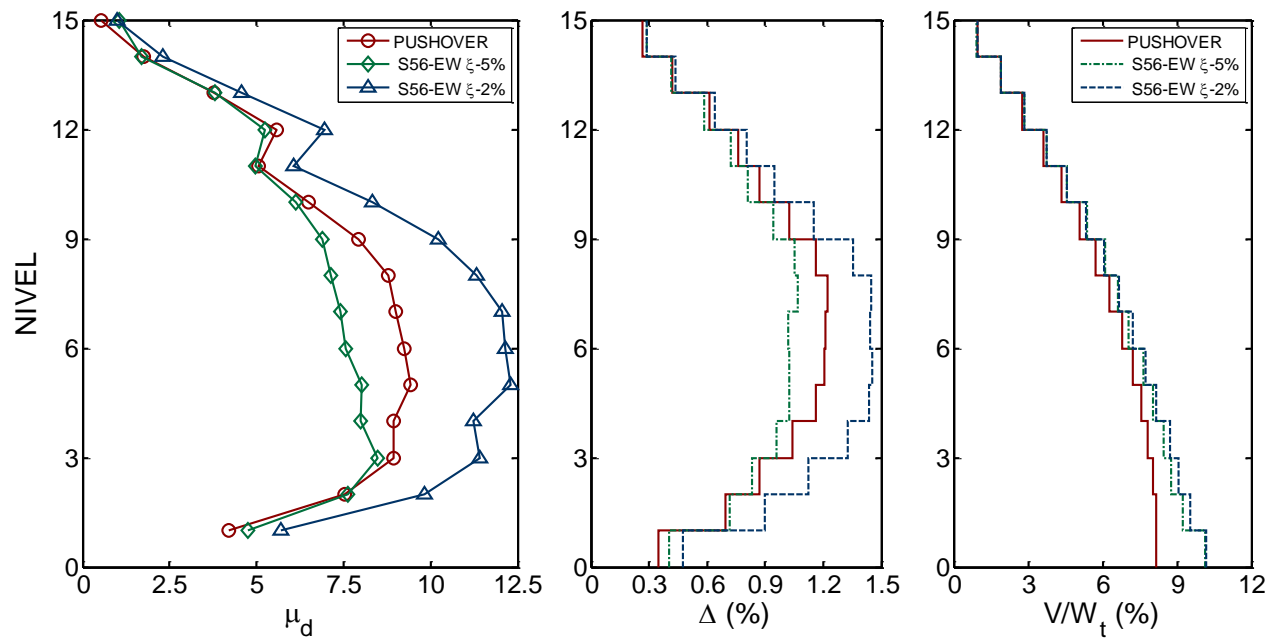

Figura 23. Comparativa de demandas de ductilidad $\mu_{d}$ de los disipadores de energía, distorsiones de entrepiso máximas y fuerzas cortantes máximas en los entrepisos, para el modelo m15 $\alpha 50 \beta 50\left(\theta=40^{0}\right.$,

$$
\left.\mathrm{k}_{2} / \mathrm{k}_{\mathrm{DDE}}=0.03\right)
$$

Finalmente, para todos los modelos de 15 niveles estudiados (estén en resonancia o no), cuando se considera un amortiguamiento viscoso equivalente $\zeta=2 \%$, como era de esperarse, las demandas máximas rebasan a las consideradas en su diseño (figuras 18, 20 y 23). Sin embargo, se demuestra nuevamente que el proceso de diseño propuesto es robusto, pues estas demandas adicionales son tomadas por la segunda línea de defensa inelástica, que son las vigas, las que en su gran mayoría desarrollan fluencias bajas (figuras $17 \mathrm{c}, 19 \mathrm{c}$ y $22 \mathrm{c})$. 
Algo que llama poderosamente la atención de los modelos en resonancia es que, en varios entrepisos, las envolventes de cortantes máximos del sistema en los análisis para $\zeta=5 \%$ resultaron mayores que para $\zeta=2 \%$ (por ejemplo, figuras 18 y 20), lo que a-priori pudiera parecer no razonable. Sin embargo, más adelante se explica con detalle el por qué esto sucede, en la discusión de los resultados de los modelos de 20 niveles, donde se observaron mayores diferencias y, por ello, es más fácil ilustrarlo.

\section{Modelos de 20 niveles}

En las figuras 24 a 29 se presentan los resultados de dos modelos que también se diseñaron con los mismos balances de rigideces, $\alpha=0.50, \beta=0.75$ y pendientes posteriores a la fluencia de los disipadores $\mathrm{k}_{2} / \mathrm{k}_{\mathrm{DDE}}=0.05$, donde nuevamente las secciones de vigas, columnas y contravientos varían bastante como resultado que las alturas de entrepiso y los ángulos de inclinación de los contravientos $(\theta)$ son distintos. De la tabla 3 se aprecia el impacto en los periodos fundamentales de vibración, que son muy distintos, $\mathrm{T}=2.162 \mathrm{~s}$ cuando $\theta=45^{\circ}$ y $\mathrm{T}=1.773 \mathrm{~s}$ cuando $\theta=40^{\circ}$. Nuevamente, si se utilizaran criterios de dinámica estructural elástica exclusivamente, ambos modelos estarían en la rama ascendente del espectro en franca resonancia (figura 21), pero su incursión al intervalo no lineal seguramente lidera a estos modelos a respuestas dinámicas menores, sobre todo el de mayor periodo, si uno emplea el concepto de espectro de demanda de ductilidad (figura 21).

De acuerdo con los análisis pushover para cada modelo, si se llevan a la ductilidad objetivo $\mu_{d}=10$ de los disipadores críticos, se espera en ambos casos un diseño 100\% resiliente (figuras 24a y 26a). Cuando se realizan los análisis dinámicos no lineales ante la acción del registro de aceleración S56-EW y suponiendo un amortiguamiento viscoso equivalente $\zeta=5 \%$, se aprecia que para el modelo más flexible $\left(\theta=45^{0}\right.$, figura 24b) se presenta una respuesta casi $100 \%$ resiliente, a excepción de la fluencia incipiente de dos vigas en el entrepiso 13. Para el modelo más rígido $\left(\theta=40^{\circ}\right.$, figura $\left.26 \mathrm{~b}\right)$, la respuesta es $100 \%$ resiliente.

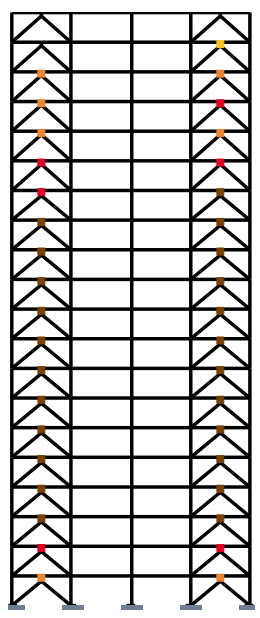

a) Pushover

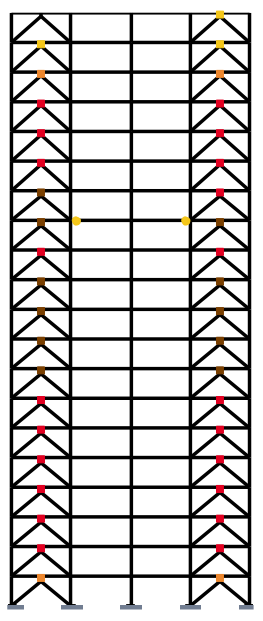

b) S56-EW $\xi=5 \%$

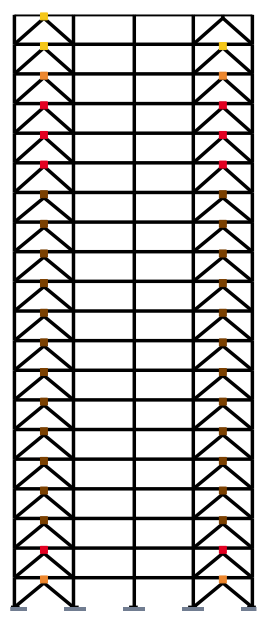

c) $\mathrm{S} 56-\mathrm{EW} \xi=2 \%$

Figura 24. Comparativa de los mapeos de fluencias inelásticas para el modelo m20 $\alpha 50 \beta 75-1\left(\theta=45^{0}\right.$, $\left.\mathrm{k}_{2} / \mathrm{k}_{\mathrm{DDE}}=0.05\right)$

De las curvas de respuestas máximas de las ductilidades de los disipadores y de las distorsiones de entrepiso máximas, se observa que cuando $\theta=45^{\circ}$ (figura 25), las curvas del análisis pushover envuelven completamente a las curvas para $\zeta=5 \%$ en los primeros 13 niveles, pero son rebasadas a partir del nivel 14, mientras que cuando $\theta=40^{\circ}$ (figura 27), las curvas del análisis pushover son excedidas a partir del nivel 9. Esto se debe a que para edificios de estas alturas y características, el impacto de los modos superiores de 
vibración en la respuesta dinámica comienza a ser más importante que para las alturas previamente estudiadas.
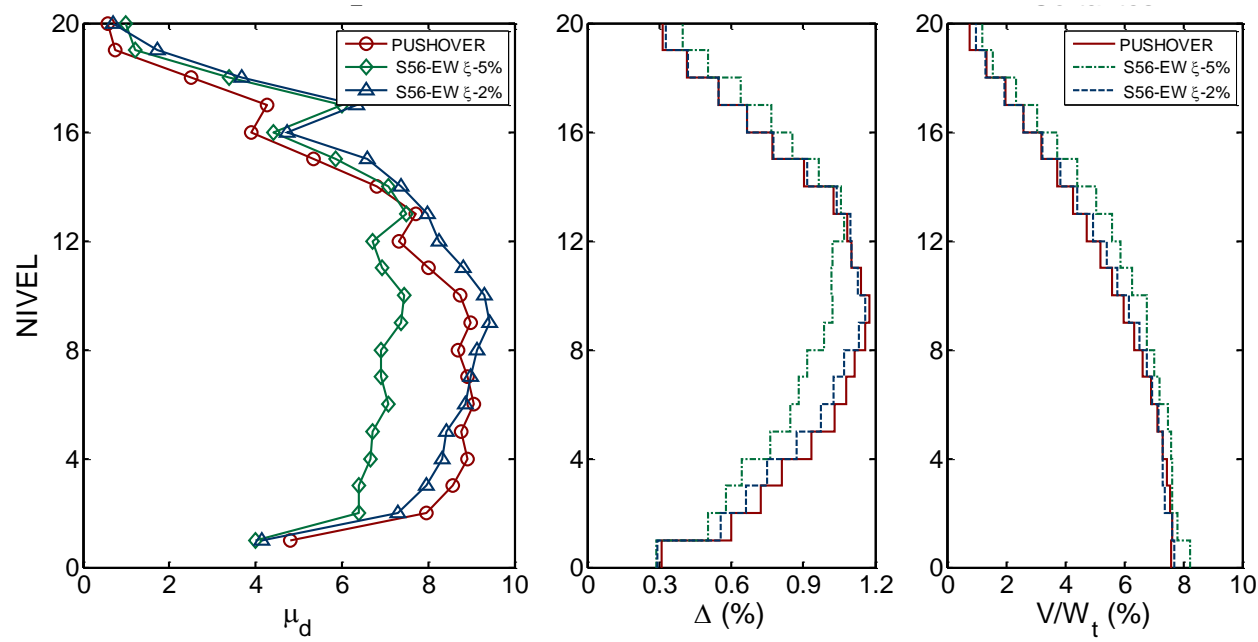

Figura 25. Comparativa de demandas de ductilidad $\mu_{d}$ de los disipadores de energía, distorsiones de entrepiso máximas y fuerzas cortantes máximas en los entrepisos, para el modelo m20 $\alpha 50 \beta 75-1\left(\theta=45^{0}\right.$, $\left.\mathrm{k}_{2} / \mathrm{k}_{\mathrm{DDE}}=0.05\right)$

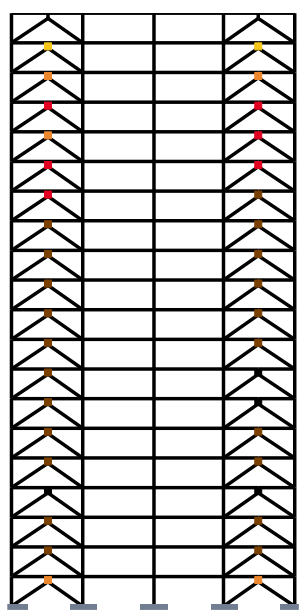

a) Pushover

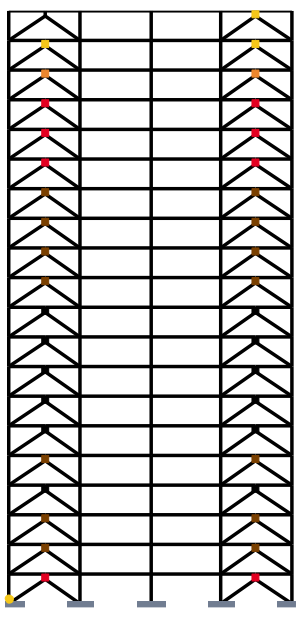

b) S56-EW $\xi=5 \%$

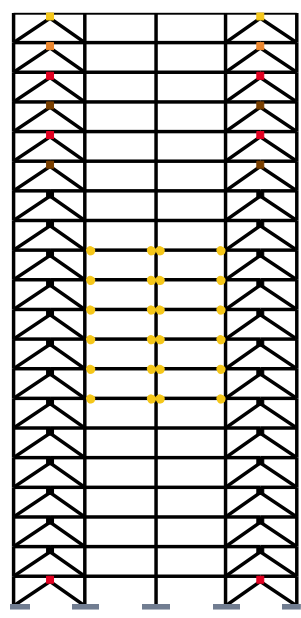

c) $\mathrm{S} 56-\mathrm{EW} \quad \xi=2 \%$

Figura 26. Comparativa de los mapeos de fluencias inelásticas para el modelo m20 $\alpha 50 \beta 75-2\left(\theta=40^{0}\right.$, $\mathrm{k}_{2} / \mathrm{k}_{\mathrm{DDE}}=0.05$ )

Finalmente, en este caso se aprecia que cuando se considera $\zeta=2 \%$, las demandas máximas envolventes rebasan ligeramente a las obtenidas con el análisis pushover para el modelo más flexible $\left(\theta=45^{0}\right.$, figura 25) y, no obstante, ello, el mapeo de fluencias es aún 100\% resiliente (figura 24c). Las demandas rebasan de manera importante a las del análisis pushover para el modelo más rígido $\left(\theta=40^{\circ}\right.$, figura 27$)$; $\sin$ embargo, el mecanismo resistente sigue siendo notablemente resiliente, pues sólo se presentan algunas fluencias incipientes en las vigas de los niveles intermedios (figura 26c). 

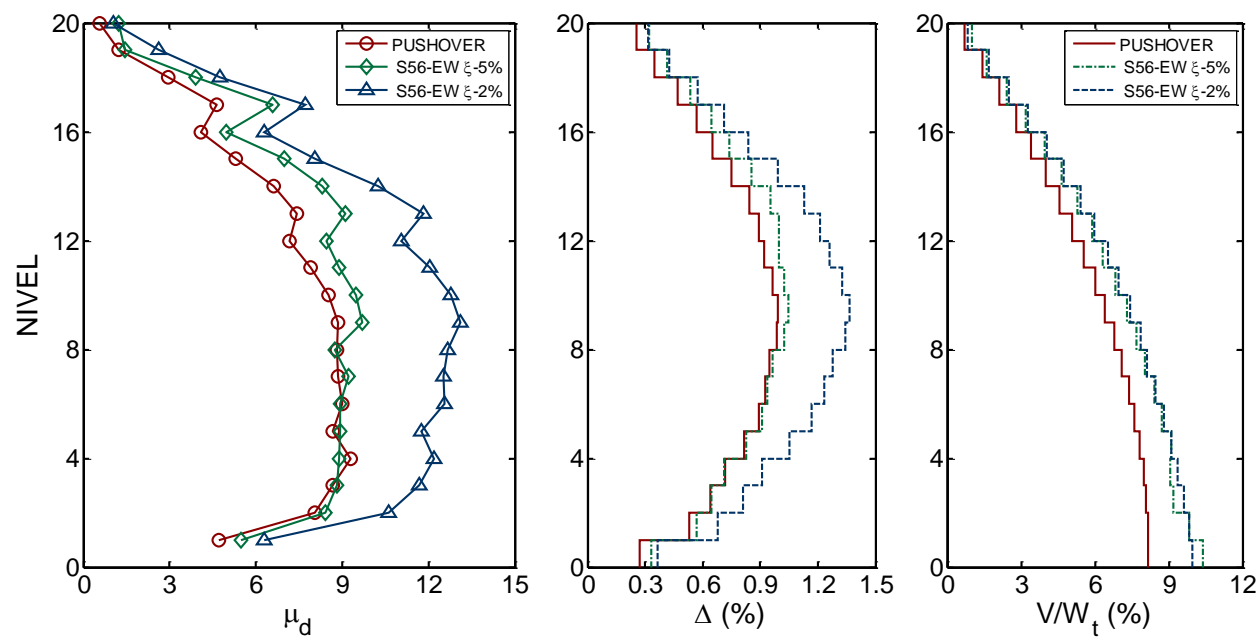

Figura 27. Comparativa de demandas de ductilidad $\mu_{d}$ de los disipadores de energía, distorsiones de entrepiso máximas y fuerzas cortantes máximas en los entrepisos, para el modelo m $20 \alpha 50 \beta 75-2\left(\theta=40^{\circ}\right.$, $\left.\mathrm{k}_{2} / \mathrm{k}_{\mathrm{DDE}}=0.05\right)$

Como se aprecia en las figuras 25 y 27, llama poderosamente la atención que, en estos modelos, las envolventes de cortantes máximos del sistema en los análisis para $\zeta=5 \%$ resultaron mayores que para $\zeta=2 \%$, sobre todo para el modelo con $\theta=45^{\circ}$, donde se observan las mayores diferencias. Con la finalidad de entender mejor el por qué sucede, cuando el sentido común indicaría, basado exclusivamente en el conocimiento de la dinámica de sistemas de un grado de libertad, que las respuestas máximas se deberían tener siempre para el sistema con menor amortiguamiento viscoso equivalente (en este caso, $\zeta=2 \%$ ), se procedió a desglosar con mayor detalle las respuestas máximas de este sistema, que es más complejo.

Así, en la figura 28 se presenta el desglose de los cortantes dinámicos máximos de entrepiso que resisten: a) todas las columnas del entrepiso ("columnas"), b) todos los contravientos-disipadores del entrepiso ("contr-disip") y, c) el sistema completo ("total"). En esta figura se aprecia que si bien se desarrollan cortantes dinámicos máximos mayores para el sistema completo (total) cuando $\zeta=5 \%$, esto se debe principalmente a que éstos provienen del sistema contraviento-disipador, donde resultan notablemente mayores para $\zeta=5 \%$ que para $\zeta=2 \%$ del nivel 1 al 18. Sin embargo, en las columnas se desarrollan, en casi todos los entrepisos, cortantes de entrepiso máximos mayores para $\zeta=2 \%$ que para $\zeta=5 \%$.

Como esta explicación exclusivamente en respuestas máximas pudiera parecer aún insuficiente, se analizaron las historias en el tiempo de los cortantes para cada entrepiso, y con fines ilustrativos se presentan en la figura 29 las del entrepiso 2, pues es un entrepiso crítico donde se aprecian, con suficiente diferencia, por una parte respuestas máximas en las columnas del entrepiso cuando $\zeta=2 \%$, pero por otra parte, respuestas máximas en el entrepiso para el sistema contraviento-disipador cuando $\zeta=5 \%$ (figura 28 ). De la observación de las historias en el tiempo de los cortantes, se comprueba un principio elemental de la dinámica estructural: cuando disminuye la intensidad de la excitación sísmica, la respuesta de un sistema con mayor amortiguamiento viscoso equivalente (en este caso, $\zeta=5 \%$ ) tiende a atenuarse o disminuir de una manera más rápida y notable que ese mismo sistema con un menor amortiguamiento viscoso equivalente (en este caso, $\zeta=2 \%$ ). Lo anterior se cumple plenamente para las historias de cortante de entrepiso de las columnas, sistema contraviento-disipador y del sistema completo, principalmente después de 160 segundos de excitación (figura 29), que es cuando el registro S56-EW reduce notablemente su intensidad (figura 6). Entonces, aunque a-priori no parezca razonable, y como se ilustra también en la figura 29, si es posible 
obtener respuestas mayores en un sistema no lineal complejo de varios grados de libertad en la fase intensa del registro para un amortiguamiento viscoso equivalente mayor $(\zeta=5 \%)$ que para uno menor $(\zeta=2 \%)$.
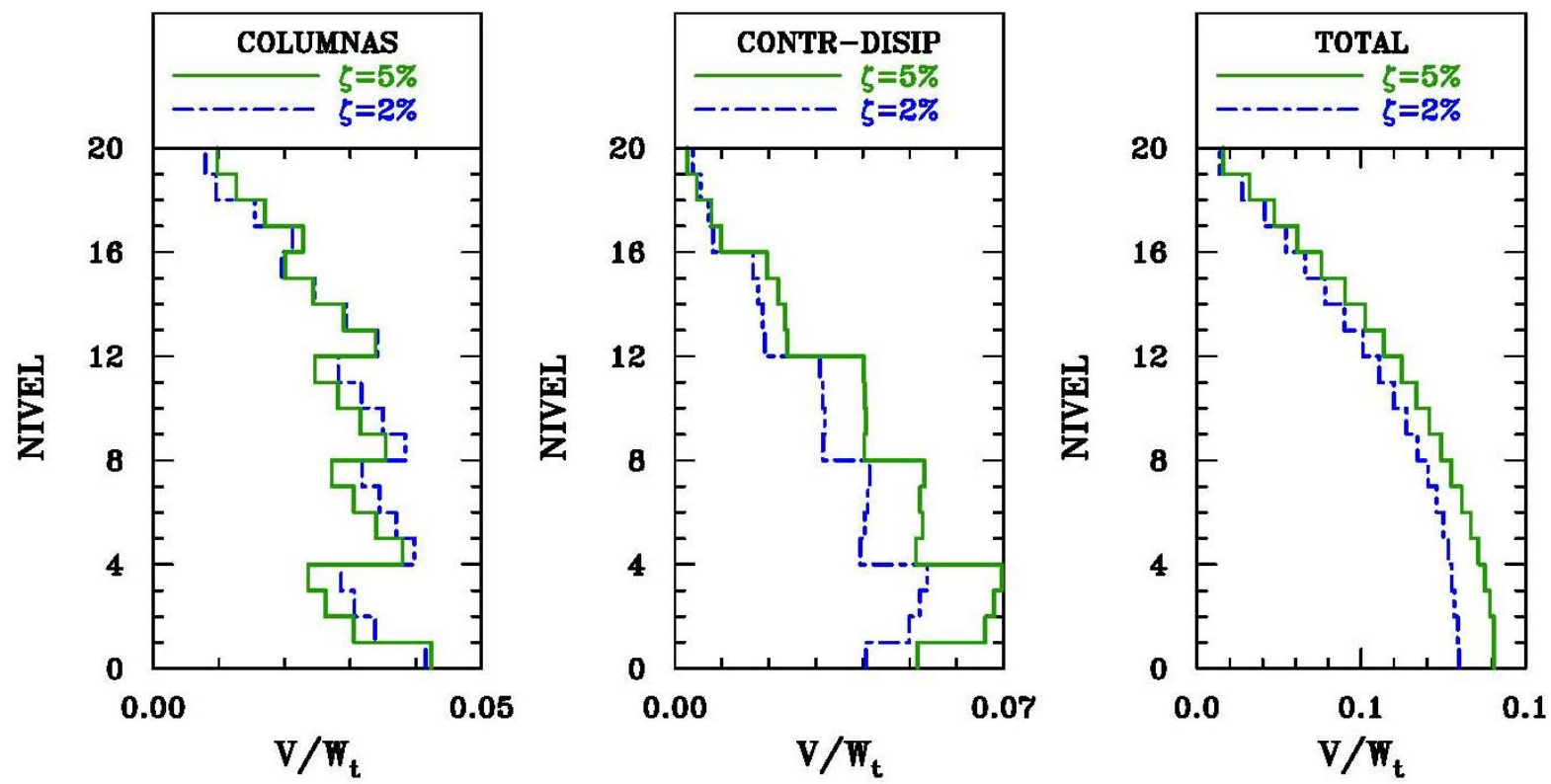

Figura 28. Comparativa de fuerzas cortantes máximas en los entrepisos para el modelo m20 $\alpha 50 \beta 75-1$ $\left(\theta=45^{0}, \mathrm{k}_{2} / \mathrm{k}_{\mathrm{DDE}}=0.05\right)$
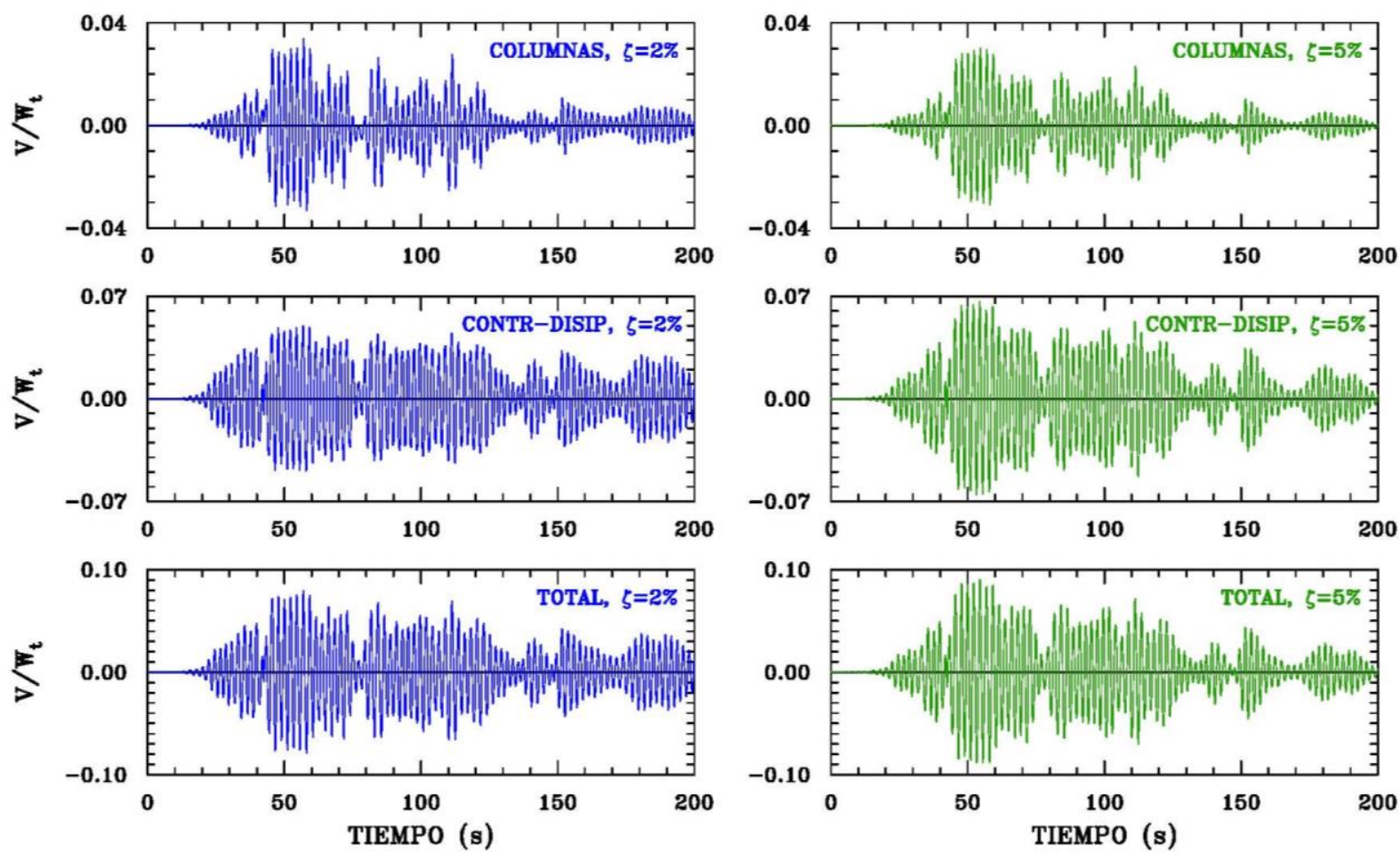

Figura 29. Comparativa de las historias de tiempo de fuerzas cortantes en los entrepisos para el modelo $\mathrm{m} 20 \alpha 50 \beta 75-1\left(\theta=45^{0}, \mathrm{k}_{2} / \mathrm{k}_{\mathrm{DDE}}=0.05\right)$ 


\section{Modelos de 25 niveles}

En las figuras 30 a 33 se presentan los resultados de dos modelos de 25 niveles, el modelo $\mathrm{m} 25 \alpha 75 \beta 25$, con parámetros $\alpha=0.75, \beta=0.25, \theta=45^{\circ}$ y $\mathrm{k}_{2} / \mathrm{k}_{\mathrm{DDE}}=0.03$, en el cual se obtuvo en el análisis pushover que se desarrollan un número importante de fluencias incipientes en vigas en los niveles intermedios cuando se alcanza la ductilidad objetivo $\mu_{\mathrm{d}}=10$ en los disipadores críticos (figura 30a), y el modelo $\mathrm{m} 25 \alpha 75 \beta 75$, con parámetros $\alpha=75, \beta=0.75, \theta=40^{0}$ y $\mathrm{k}_{2} / \mathrm{k}_{\mathrm{DDE}}=0.03$, en el cual del análisis pushover se obtiene un mecanismo totalmente resiliente a la ductilidad objetivo $\mu_{\mathrm{d}}=10$ en los disipadores críticos (figura 32a).

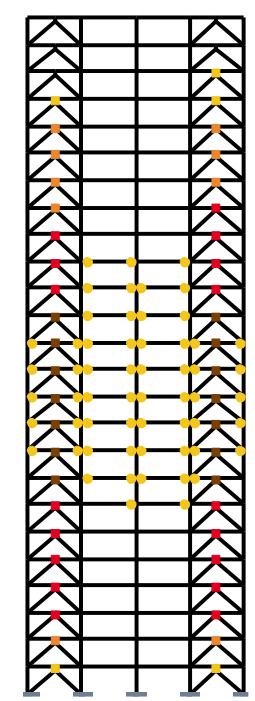

a) Pushover

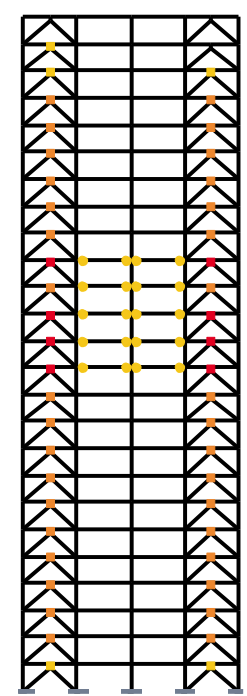

b) S56-EW $\xi=5 \%$

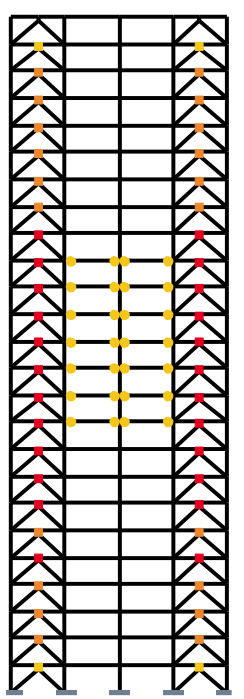

c) $\mathrm{S} 56-\mathrm{EW} \xi=2 \%$

Figura 30. Comparativa de los mapeos de fluencias inelásticas para el modelo m $25 \alpha 75 \beta 25\left(\theta=45^{0}\right.$,

$$
\mathrm{k}_{2} / \mathrm{k}_{\mathrm{DDE}}=0.03 \text { ) }
$$
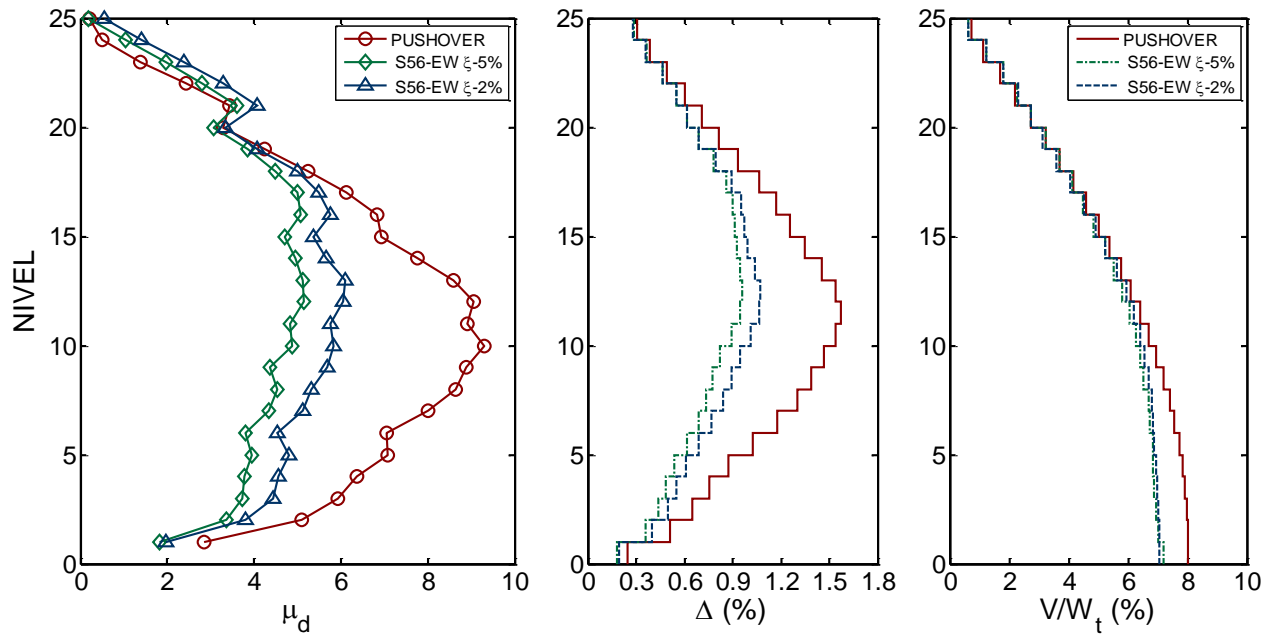

Figura 31. Comparativa de demandas de ductilidad $\mu_{d}$ de los disipadores de energía, distorsiones de entrepiso máximas y fuerzas cortantes máximas en los entrepisos, para el modelo m $25 \alpha 75 \beta 25\left(\theta=45^{0}\right.$, $\mathrm{k}_{2} / \mathrm{k}_{\mathrm{DDE}}=0.03$ ) 
Para el primer modelo (m25 $\alpha 75 \beta 25)$, el periodo fundamental de vibración es $\mathrm{T}=2.295 \mathrm{~s}$, por lo que de entrada se encuentra cercano, pero en la rama descendente de la resonancia elástica para el registro en consideración (figuras 6 y 21). Es por ello que, en los análisis dinámicos no lineales ante el registro S56$\mathrm{EW}$, las respuestas máximas para $\zeta=5 \%$ y aún para $\zeta=2 \%$ quedan perfectamente envueltas por las obtenidas en el análisis pushover, salvo las demandas de ductilidad de los disipadores entre los niveles 21 y 25 , por el impacto de los modos superiores (figura 31). Por ello, los mapeos de fluencias desarrollados son de menor intensidad (figuras 30b y 30c) y quedan perfectamente envueltos por el mapeo obtenido para el análisis pushover (figura 30a).

Para el segundo modelo (m25 $\alpha 75 \beta 75$ ), el periodo fundamental de vibración es $\mathrm{T}=1.851 \mathrm{~s}$, y en este caso se espera que, de entrada, el modelo entre a la franja de respuesta resonantes (figuras 6 y 21 ), para después, en el intervalo no lineal, responda en una franja de demanda ligeramente menor. A pesar de ello, el mapeo de fluencias para $\zeta=5 \%$ (figura 32b) concuerda muy bien con el del análisis pushover (figura 32a), pues sólo se desarrollan fluencias incipientes en dos vigas, además de la fluencia de dos columnas de PB en su base, lo que está dentro de lo tolerable en un diseño resiliente ante una acción extrema. Las curvas de respuestas máximas de demandas de ductilidad y de distorsiones de entrepiso son muy cercanas y en general bien envueltas por las del análisis pushover; sólo las exceden ligeramente en los niveles 1 a 3 y 16 a 25 (figura 33). Las fuerzas cortantes máximas de entrepiso si resultan mayores entre un $10 \%$ y un $20 \%$ con respecto a las estimadas en el análisis pushover (figura 33), pero se debe recordar también que estos modelos se diseñaron para un cortante basal $10 \%$ menor y que el acelerograma considerado rebasa al espectro de diseño elástico (figura 6).

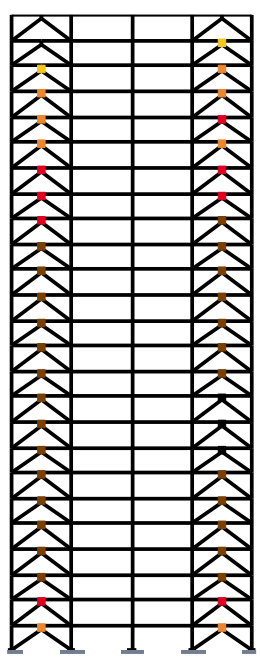

a)
Pushover

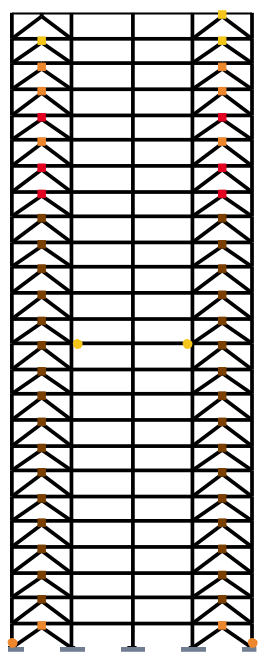

b) S56-EW $\xi=5 \%$

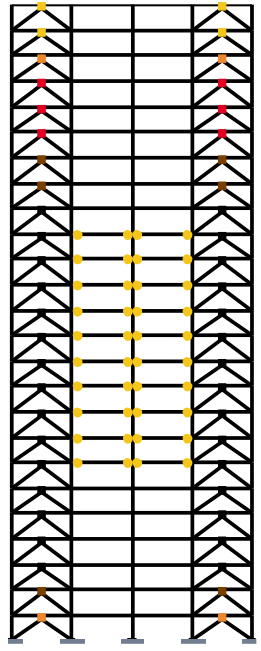

c) $\mathrm{S} 56-\mathrm{EW} \xi=2 \%$

Figura 32. Comparativa de los mapeos de fluencias inelásticas para el modelo m $25 \alpha 75 \beta 75\left(\theta=40^{\circ}\right.$, $\mathrm{k}_{2} / \mathrm{k}_{\mathrm{DDE}}=0.03$ )

De la observación de los resultados obtenidos para $\zeta=2 \%$ se confirma la robustez del procedimiento de diseño propuesto, pues si se exceden de manera importante las premisas de diseño (demandas de ductilidad máximas objetivo de los disipadores, distorsiones y cortantes de entrepiso, figura 33), se activa el segundo mecanismo de defensa inelástica, que son las vigas, pero sólo se desarrollan fluencias incipientes (figura 32c). 

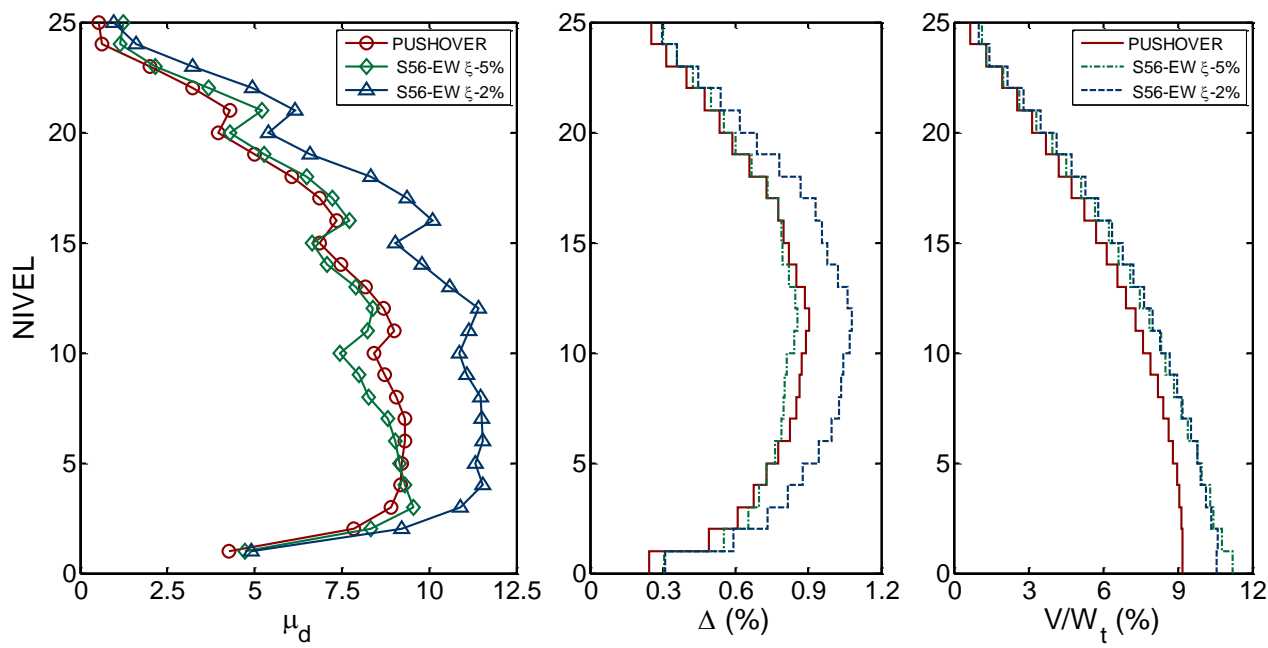

Figura 33. Comparativa de demandas de ductilidad $\mu_{d}$ de los disipadores de energía, distorsiones de entrepiso máximas y fuerzas cortantes máximas en los entrepisos, para el modelo m $25 \alpha 75 \beta 75\left(\theta=40^{0}\right.$, $\mathrm{k}_{2} / \mathrm{k}_{\mathrm{DDE}}=0.03$ )

\section{COMENTARIOS FINALES Y CONCLUSIONES}

En este trabajo se presentaron los resultados de los análisis dinámicos no lineales de doce modelos de edificios que se diseñaron conforme a una metodología que emplea el método de las fuerzas y principios de diseño por capacidad y de fusible estructural, la cual permite obtener diseños sísmicos resilientes de estructuras con base en marcos contraventeados de acero estructural dúctiles con disipadores de energía histeréticos.

La robustez del procedimiento de diseño por capacidad y resiliente propuesto, así como la validez de los parámetros globales de diseño sísmico $\left(Q, R, \Delta_{y}\right.$ y $\left.\Delta_{u}\right)$ y de los balances de rigideces iniciales (elásticas) entre el sistema del marco y el sistema total $(\alpha)$, así como entre el disipador y el contraviento de soporte $(\beta)$ propuestos y explicados con detalles en trabajos anteriores, se comprueba con la comparación de la respuesta obtenida para 12 modelos críticos con análisis dinámicos no lineales paso a paso, con respecto a obtenida en análisis estáticos no lineales ante carga monótona creciente (pushover), con los cuáles se definieron los mecanismos de diseño resiliente y los parámetros globales de diseño sísmico.

Se confirma y demuestra que los mecanismos de diseño sísmico resiliente obtenidos mediante análisis pushover, donde esencialmente los disipadores de energía son casi exclusivamente los que trabajan inelásticamente, funcionando como fusibles estructurales, permitiendo cuando más que se desarrollen algunas fluencias incipientes (baja intensidad) en unas cuantas vigas, se cumplen para la enorme mayoría de los 12 modelos estudiados ante una acción de diseño extrema compatible con las premisas de diseño de los modelos, que corresponde a los resultados obtenidos para el registro artificial S56-EW para $\zeta=5 \%$, aun en casos que los modelos respondan dinámicamente en la franja resonante. También se comprueba que, si la excitación dinámica rebasa los parámetros de resistencia o demanda supuestos en el diseño de los modelos, que corresponde a los resultados obtenidos para el registro artificial S56-EW para $\zeta=2 \%$, cuando más se activa la segunda línea de defensa del sistema, que es la fluencia de algunas vigas del marco, y cabe resaltar que éstas son incipientes y en un número muy reducido de vigas, aún en casos donde la estructura responde en la franja resonante. 
Con base en los resultados presentados y expuestos, se confirma que es muy factible diseñar resilientemente a estructuras con base en marcos contraventeados de acero estructural dúctiles con disipadores de energía histeréticos, empleando el método de las fuerzas y principios de diseño por capacidad y de fusible estructural. Esto incluye a edificios altos y esbeltos (modelos de 20 y 25 niveles), donde si cabe señalar que la respuesta de los modos superiores empieza a ser importante en la respuesta de los últimos niveles. Por lo tanto, se pueden emplear con confianza los parámetros globales de diseño sísmico y balances óptimos de rigideces $\alpha$ y $\beta$ derivados a partir de los análisis pushover, así como los valores obtenidos para los parámetros globales de diseño sísmico $Q, R, \Delta_{y}$ y $\Delta_{u}$.

Finalmente, los autores consideran muy importante enfatizar, como se ha demostrado en este estudio, que para sistemas no lineales, las respuestas resonantes se producen en periodos fundamentales elásticos inferiores al periodo asociado a la resonancia elástica, y tienden a alejarse más de éste conforme más se reduce la resistencia normalizada de fluencia, cuando el resto de las características que definen al modelo histerético permanecen invariables. Es por ello que abusar de la reducción de fuerzas de diseño por concepto de ductilidad, considerando ductilidades muy grandes, sin tomar en cuenta cómo esto afecta las respuestas dinámicas de una estructura cualquiera, es una práctica muy peligrosa en el diseño sismorresistente de estructuras, que puede liderar a muchas estructuras a respuestas indeseables, incluso a un colapso no contemplado. Esta observación es general, y no se limita exclusivamente al sistema estructural en estudio, es algo que ya se ha demostrado previamente también para otros sistemas estructurales.

\section{AGRADECIMIENTOS}

Héctor Hernández Ramírez agradece la beca otorgada por el Consejo Nacional de Ciencia y Tecnología de México (Conacyt), que le permitió involucrarse en este proyecto de investigación en el desarrollo de su tesis de maestría en el Posgrado de Ingeniería Estructural de la UAM Azcapotzalco. Los autores agradecen al Dr. Luis Eduardo Pérez Rocha el haber generado el acelerograma sintético para la estación CO56 empleado en este estudio.

\section{REFERENCIAS}

Aguiar, R, L García, E Menéndez, M Zevallos y J Palacios (2016a), “Análisis y reforzamiento de una estructura afectada por el terremoto del 16 de abril de 2016", Revista Ingeniosos, Vol. 1, Art. 1, pp. 1-16, marzo-septiembre.

Aguiar, R, M Rodríguez y D Mora (2016b), “Análisis sísmico de estructuras con disipadores de energía ADAS o TADAS”, Monografía CIMNE IS-75, Centro Internacional de Métodos Numéricos en Ingeniería, Barcelona, España, ISBN: 978-84-945077-5-5.

Benedetti, A, L Landi y D G Merenda (2014), "Displacement-based design of an energy dissipating system for seismic upgrading of existing masonry structures", Journal of Earthquake Engineering, Vol. 18, No. 4, pp. 477-501, DOI: 10.1080/13632469.2014.897274.

Chen, Z Y, H Ge, A Kasai y T Usami (2007), "Simplified seismic design approach for steel portal frame piers with hysteretic dampers", Earthquake Engineering and Structural Dynamics, Vol. 36, No. 4, pp. 541-562. DOI: $10.1002 /$ eqe. 643

Del Valle, E (1988), "Amortiguamiento adicional para reducir efectos sísmicos", Revista de Ingeniería Sísmica, No. 32, pp. 49-76. 
Foti, D, L M. Bozzo y F López-Almansa (1998), "Numerical efficiency assessment of energy dissipators for seismic protection of buildings", Earthquake Engineering and Structural Dynamics, Vol. 27, pp. 543-556. DOI: 10.1002/(SICI)1096-9845(199806)27:6<543::AID-EQE733>3.0.CO;2-9

Hernández, H (2015), "Propuesta de diseño sísmico para marcos de acero con disipadores de energía histeréticos", Tesis de Maestría, Posgrado en Ingeniería Estructural, División de Ciencias Básicas e Ingeniería, Universidad Autónoma Metropolitana Azcapotzalco, julio.

Nangullasmú, H J y A Tena (2016), "Requisitos mínimos de detallado dúctil en marcos de concreto reforzado protegidos con disipadores histeréticos de energía”, Revista de Ingeniería Sísmica, No. 95, pp. 1-32, julio-diciembre, DOI: 10.18867/ris.95.381.

NTCS-04 (2004), "Normas Técnicas Complementarias para Diseño por Sismo", Gaceta Oficial del Distrito Federal, Tomo II, No. 103-BIS, octubre.

Ramírez, O M, M C Constantinou, C A Kircher, A S Whittaker, M W Johnson, J D Gómez y C Z Chryzostomou (2001), "Development and evaluation of simplified procedures for analysis and design of buildings with passive energy dissipation systems", Technical Report MCEER-00-0010, Multidisciplinary Center for Earthquake Engineering Research, State University of New York at Buffalo.

Rosenblueth, E, M Ordaz, F J Sánchez-Sesma y S K Singh (1989), "The Mexico earthquake of September 19, 1985 - Design spectra for Mexico's Federal District”, Earthquake Spectra, Vol. 5, No. 1, pp. 273291. DOI: $10.1193 / 1.1585523$

Scholl, R E (1993), "Fundamental design issues for supplemental damping applications", Earthquake Spectra, Vol. 9, No.3, pp. 627-636. DOI: 10.1193/1.1585732

Symans, M D, F A Charney, A S Whittaker, M C Constantinou, C A Kircher, M W Johnson y R J McNamara (2008), "Energy dissipation systems for seismic applications: current practice and recent developments", ASCE Journal of Structural Engineering, Vol. 134, No. 1, pp. 3-21. DOI: $\underline{10.1061 /(A S C E) 0733-9445(2008) 134: 1(3)}$

Tena, A (1997), "Espectros inelásticos de demandas de ductilidad para la evaluación de estructuras existentes ante sismos", Memorias, XI Congreso Nacional de Ingeniería Sísmica, Veracruz, Veracruz, Vol. I, pp. 671-682, noviembre.

Tena, A (1998a), "Modelado analítico de edificios con disipadores de energía, aplicaciones en proyectos de reestructuración", Memorias, V Simposio Nacional de Ingeniería Sísmica: Disipadores de energía para controlar la respuesta sísmica de edificios, Toluca, Estado de México, pp. 85-120, septiembre.

Tena, A (1998b), "Evaluación sísmica simplificada de estructuras existentes", Revista de Ingeniería Sísmica, No. 59, pp. 29-62, julio-diciembre, DOI: 10.18867/ris.59.251.

Tena, A (2000), "Modelado analítico de edificios con disipadores de energía", Revista de Ingeniería Sísmica, No. 62, pp. 29-62, DOI: 10.18867/ris.62.253 .

Tena, A (2010), “A 25 años del sismo de septiembre de 1985: Breves reflexiones sobre los espectros de diseño sísmico", Memorias, XI Simposio Nacional de Ingeniería Sísmica, a 25 años del sismo de 1985: Aprendizaje, Conciencia y Prevención, México, DF, CDROM, pp. 1-9, septiembre.

Tena, A y H J Nangullasmú (2013), "Diseño sísmico de marcos no dúctiles de concreto reforzado con disipadores de energía histeréticos. Definición de parámetros de diseño", Revista Internacional de Desastres Naturales, Accidentes e Infraestructura Civil, Vol. 13, No. 2, pp. 275-299.

Tena, A, H J Nangullasmú, H Hernández y A Gama (2016), "Diseño sísmico conforme a reglamento de edificios estructurados con base en marcos contraventeados con disipadores de energía histeréticos", 
Memorias, XIV Simposio Nacional de Ingeniería Sísmica, León, Guanajuato, CDROM, pp. 1-57, junio-julio.

Tena, A y H Hernández (2016), "Definición de parámetros globales de diseño sísmico de marcos dúctiles de acero con disipadores de energía histeréticos", Revista Internacional de Desastres Naturales, Accidentes e Infraestructura Civil, Vol. 16, No. 1, pp. 19-47.

Tena, A y H Hernández (2017), "Diseño sísmico resiliente de marcos dúctiles de acero con fusibles estructurales", Revista Internacional de Ingeniería de Estructuras, Vol. 22, No. 4, pp. 421-457.

Tena, A y A Gama (2017), "Determinación de parámetros de diseño sísmico para marcos dúctiles de concreto reforzado con disipadores de energía histeréticos", Revista Sul-americana de Engenharia Estrutural, Vol. 14, No. 1, pp. 36-58, DOI: 10535/rsaee.v14i1.6496.

Tena-Colunga, A y D Pérez-Moreno (1994), “Seismic upgrading of a nine-story building at Mexico City's lake-bed zone using U-Shaped energy dissipation devices", Memorias, 9th International Seminar on Earthquake Prognostics, San José, Costa Rica, septiembre, DOI:10.13140/2.1.1991.9684.

Tena-Colunga, A, E Del Valle y D Pérez-Moreno (1996), "Issues on the seismic retrofit of a building near resonant response and structural pounding", Earthquake Spectra, Vol. 12, No. 3, pp. 567-597, DOI: $\underline{10.1193 / 1.1585897 .}$.

Tena-Colunga, A y A Vergara (1997), "Comparative study on the seismic retrofit of a mid-rise steel building: steel bracing vs energy dissipation", Earthquake Engineering \& Structural Dynamics, Vol. 26, No. 6, pp. 637-645, DOI: 10.1002/(SICI)1096-9845(199706)26:6<637::AID-EQE666>3.0.CO;2$\underline{\mathrm{R}}$.

Tena-Colunga, A (2001), "Displacement ductility demand spectra for the seismic evaluation of structures", Engineering Structures, Vol. 23, No. 10, pp. 1319-1330, DOI: 10.1016/S0141-0296(01)00025-6 .

Tena-Colunga, A (2007), "State of the Art and State of the Practice for energy dissipation and seismic isolation of structures in Mexico", Memorias, 10th World Conference on Seismic Isolation, Energy Dissipation and Active Vibration Control of Structures, Estambul, Turquía, CD-ROM, mayo.

Tena-Colunga, A y H J Nangullasmú-Hernández (2015), “Assessment of seismic design parameters of moment resisting RC braced frames with metallic fuses", Engineering Structures, Vol. 95, pp. 138153, DOI: 10.1016/j.engstruct.2015.03.062.

Tena-Colunga, A y H Hernández-Ramírez (2017), "Code-oriented global design parameters for momentresisting steel frames with metallic structural fuses", Frontiers in Built Environment, Vol. 3, Article 19, DOI: 10.3389/fbuil.2017.00019 .

Vargas, R y M Bruneau (2006), "Analytical investigation of the structural fuse concept", Technical Report MCEER-06-0004, Multidisciplinary Center for Earthquake Engineering Research, University at Buffalo, State University of New York, March.

Vargas, R y M Bruneau (2009), "Analytical response and design of buildings with metallic structural fuses. I", ASCE Journal of Structural Engineering, Vol. 135, No. 4, pp. 386-393. DOI: 10.1061/(ASCE)0733-9445(2009)135:4(386)

Wu, J y R E Hanson (1987), "Inelastic response of structures with high damping subjected to earthquakes", Report UMCE 87-9, Department of Civil Engineering, The University of Michigan, noviembre. 